\title{
Estimating Time Preferences from Convex Budgets
}

\author{
By JAMEs Andreoni And Charles Sprenger*
}

\begin{abstract}
Experimentally elicited discount rates are frequently higher than what seems reasonable for economic decision-making. Such high rates are often attributed to present-biased discounting. A well-known bias of standard measurements is the assumption of linear consumption utility. Attempting to correct this bias using measures of risk aversion to identify concavity, researchers find reasonable discounting but at the cost of exceptionally high utility function curvature. We present a new methodology for identifying time preferences, both discounting and curvature, from simple allocation decisions. We find reasonable levels of both discounting and curvature and, surprisingly, dynamically consistent time preferences. (JEL C91, D12, D81)
\end{abstract}

Understanding and estimating time preferences is obviously of great importance to economists, marketers, and policy makers. Consumers decide how much to invest in savings, education, real estate, and life insurance, how much to diet, exercise, and smoke, whether to marry, when to have children, and what to leave in their wills.

While there has been substantial research estimating time preferences using aggregate consumption data, ${ }^{1}$ the bulk of the effort has occurred in laboratory environments. ${ }^{2}$ Among the many laboratory techniques employed, recent studies have favored multiple price lists (MPL) with monetary payments. ${ }^{3}$

With MPLs, individuals are asked multiple times to choose between smaller payment amounts closer to the present and larger amounts further into the future. The interest rate increases monotonically in a price list, such that the point where an individual switches from preferring sooner payments to later payments carries interval

\footnotetext{
*Andreoni: University of California, San Diego, Department of Economics, 9500 Gilman Drive, La Jolla, CA 92093 (e-mail: andreoni@ucsd.edu); Sprenger: Stanford University, Department of Economics, Landau Economics Building, 579 Serra Mall, Stanford, CA 94305 (e-mail: cspreng@ @tanford.edu). We are grateful for the insightful comments of four anonymous referees, and our many colleagues, including Nageeb Ali, Douglas Berhneim, Michèlle Cohen, Tore Ellingsen, Ed Glaeser, Glenn Harrison, David Laibson, Antonio Rangel, Al Roth, Andrew Schotter, and participants at the Economics and Psychology lecture series at Paris 1, the Psychology and Economics segment at Stanford Institute of Theoretical Economics 2009, the Amsterdam Workshop on Behavioral and Experimental Economics 2009, the Harvard Experimental and Behavioral Economics Seminar, and members of the graduate experimental economics courses at Stanford University and the University of Pittsburgh. We also acknowledge the generous support of the National Science Foundation, grant SES-0962484 (Andreoni) and grant SES-1024683 (Andreoni and Sprenger).

${ }^{\dagger}$ To view additional materials, visit the article page at http://dx.doi.org/10.1257/aer.102.7.3333.

${ }^{1}$ Examples include Hausman (1979); Gourinchas and Parker (2002); Cagetti (2003); Laibson, Repetto, and Tobacman $(2003,2005)$.

${ }^{2}$ For a survey of the literature, see Frederick, Loewenstein and O'Donoghue (2002). Recent contributions include Harrison, Lau, and Williams (2002); Harrison et al. (2005); Andersen et al. (2008); Benhabib, Bisin, and Schotter (2010); Tanaka, Camerer, and Nguyen (2010).

${ }^{3}$ The MPL with monetary payments in economics was motivated and popularized by Coller and Williams (1999) and Harrison, Lau, and Williams (2002). In psychology, a similar technique was employed by Kirby, Petry, and Bickel (1999) and has been implemented in several economic laboratory experiments, including Chabris et al. (2008a, b).
} 
information about their intertemporal preferences. Assuming time-separable stationary preferences and linear utility, individual discount rates can be bounded and potentially calculated from MPL switching points. ${ }^{4}$

A notable feature of MPLs (and other experimental methods) is that they yield high average discount rates. Estimates of annual discount rates over one hundred percent are common (Frederick, Loewenstein, and O'Donoghue 2002). This is curiously at odds with aggregate models of discounting which imply much lower annual discount rates (Gourinchas and Parker 2002; Cagetti 2003). A possible explanation for this difference may lie in experimenters' frequent assumption of linear utility, which leads to upward-biased discount rate estimates if utility is concave..$^{5}$ An important step in correcting this bias comes from Andersen et al. (2008) who separately administered MPLs and price list risk preference measures based on Holt and Laury (2002) (HL) to the same subjects. Using both time and risk price lists, they jointly estimated discounting and curvature parameters..$^{6}$ For brevity, we refer to this as the Double Multiple Price List (DMPL) approach. ${ }^{7}$

In this paper, we use a single, simple instrument to capture both discounting and concavity of utility. Notice that the binary choice of an MPL task is akin to intertemporal optimization subject to a discontinuous budget. Though under linear preferences the discontinuity does not influence choice, individuals with concave utility will be constrained. The potentially problematic discontinuity suggests a simple solution: convexify the experimental budgets. Hence, we call our approach the Convex Time Budget (CTB) method.

Intertemporal allocations in CTBs are solutions to standard intertemporal constrained optimization problems. Analysis of the allocations is straightforward. Given a set of functional form assumptions about discounting and curvature of the utility function, preference parameters are estimable at either the group or individual level. Unlike preference parameters estimated from MPL data, which are identified as a set of possible values, CTBs allow for point identification of preference parameters. Additionally, structural assumptions such as the dynamic consistency of time preferences can be tested in simple and familiar ways.

In a computerized experiment with 97 subjects, we show that the CTB method can be used to generate precise estimates of discounting and curvature parameters at both the aggregate and individual levels. These estimates require a minimal set

\footnotetext{
${ }^{4}$ Price list switch points indicate approximately where sooner and later payments are equally valued. Take a sooner payment $c_{t}$, a later payment $c_{t+k}$, and a utility function $U\left(c_{t}, c_{t+k}\right)$. Under time-separable stationary utility, $U\left(c_{t}, c_{t+k}\right)=u\left(c_{t}\right)+\delta^{k} u\left(c_{t+k}\right)$ and a switch point indicates where $u\left(c_{t}\right) \approx \delta^{k} u\left(c_{t+k}\right)$. Under linear utility, $u(c)=c$ and $\delta$ is calculated as $\delta \approx\left(c_{t} / c_{t+k}\right)^{1 / k}$. Discount rates are then calculated as $I D R=(1 / \delta)-1$.

${ }^{5}$ Under linear utility, $u\left(c_{t}\right)=c_{t}$ and $\delta$ is calculated as $\delta_{L} \approx\left(c_{t} / c_{t+k}\right)^{1 / k}$. Rabin (2000) shows that under expected utility theory, individuals should have approximately linear preferences for small stakes outcomes, such as those normally used in time preference experiments. However, a variety of studies show substantial curvature over small stakes outcomes (e.g., Holt and Laury 2002). If there is curvature to the utility function, then $\delta_{C} \approx\left(u\left(c_{t}\right) / u\left(c_{t+k}\right)\right)^{1 / k}$. The direction of the bias $\delta_{C}-\delta_{L}$ depends on the shape of the utility function. Concavity generates downwardbiased discount factor (upward-biased discount rate) estimates.

${ }^{6}$ Frederick, Loewenstein, and O'Donoghue (2002) propose a similar strategy of separately identifying the utility function and discounting along with two other approaches for distinguishing time preferences from curvature: (i) eliciting utility judgements such as attractiveness ratings at two points in time; and (ii) eliciting preferences over temporally separated probabilistic prospects to exploit the linearity-in-probability property of expected utility. The second approach is employed by Anderhub et al. (2001).

${ }^{7}$ Tanaka, Camerer, and Nguyen (2010) employ a similar approach with a risk price list task designed to elicit loss aversion. However, they do not use the risk price list to inform curvature of the utility function in estimation of time preference parameters.
} 
of structural assumptions and are easily implemented econometrically. On average, estimates of individual discount rates are found to be considerably lower than in previous studies. Across specifications, we estimate average annual discount rates between 25 and 35 percent. We reject linearity of utility, although we find far less curvature than prior studies using price lists for risk preferences. Indeed, almost 35 percent of subjects exhibit behavior that is fully consistent with linear preferences. Finally, to our surprise, we find no evidence of present-bias or hyperbolic discounting.

We also compare within-subjects results of the computerized CTB and those obtained using a standard paper-and-pencil DMPL. Our design allows us to make individual level comparisons. Interestingly, though individual discounting correlates highly across elicitation mechanisms, estimated curvature from CTBs is found to be independent of DMPL risk experimental responses.

Our results raise several important questions for future research. First, why did we find no evidence of present bias or hyperbolic discounting? One hypothesis is that this may be the result of measures we took to equate transaction costs of sooner and later payments and to increase confidence of receiving future payments. This interpretation suggests that some of the behavior attributed to present bias in the literature may actually be an artifact of differential risk or transactions costs over sooner and later payments. We explore this hypothesis in a separate experiment (Andreoni and Sprenger 2012b). A second, more fundamental, question is whether we should have expected to find present bias? Though present bias has been demonstrated many times in experiments using money, the underlying psychological models of temptation and self-control (Laibson 1997; O'Donoghue and Rabin 1999; Gul and Pesendorfer 2001) make clear that present bias is about consumption utility rather than money. Indeed, if subjects have access to even modest amounts of liquidity, researchers should be surprised to measure any present bias in experiments with monetary rewards..$^{8}$ Third, we find substantial within-subject differences between our CTB and DMPL measures of utility function curvature. This may suggest a real difference in the utility parameters that apply in uncertain and certain environments. Utility differences across certainty and uncertainty arise in some form in many static and intertemporal models of decision making (Selden 1978; Kreps and Porteus 1978; Epstein and Zin 1989; Schoemaker 1982; Neilson 1992; Schmidt 1998; Diecidue, Schmidt, and Wakker 2004) and were originally suggested by Allais (1953).

The paper proceeds as follows: Section I explains the motivation of the CTB and design for the CTB experiment. Section II outlines several econometric specifications while Section III presents group and individual analysis. Section IV concludes.

\section{Experimental Design: Convex Time Budgets}

In each decision of an MPL, subjects choose either an amount $c_{t}$, available at time $t$, or an amount $c_{t+k}>c_{t}$, available after a delay of $k>0$ periods. Let $(1+r)$ be the

\footnotetext{
${ }^{8}$ We thank Matthew Rabin for persistently and amicably reminding us of this point.
} 
experimental gross interest rate and $m$ be the experimental budget..$^{9}$ Assuming some utility function, $U\left(c_{t}, c_{t+k}\right)$, the MPL task asks subjects to maximize utility subject to the discrete budget set:

$$
\left((1+r) c_{t}, c_{t+k}\right) \in\{(m, 0),(0, m)\}
$$

Assuming linear utility, the corner solution constraints of (1) are nonbinding. However, if utility is concave, the constraints bind. One cannot infer discounting from MPL switch points.

Imagine, instead of $(1)$, subjects choose $c_{t}$ and $c_{t+k}$ continuously along a convex budget set:

$$
(1+r) c_{t}+c_{t+k}=m
$$

This is a standard future-value budget constraint. To operationalize (2) we provide subjects with a budget of experimental "tokens." Tokens can be allocated to either a sooner time $t$, or a later time $t+k$, at different "token exchange rates." The relative rate at which tokens translate into payments determines the gross interest rate, $(1+r)$. Subjects choose how many tokens to allocate to sooner and later periods. This is our Convex Time Budget (CTB) approach.

Substantial information can be obtained from allocations in this convex choice environment. Variations in delay lengths, $k$, and interest rates, $(1+r)$, allow for the identification of time discounting and utility function curvature. Variations to starting times, $t$, allow for the identification of present bias and hyperbolic discounting.

\section{A. CTB Design Features}

Our experiment was conducted at the University of California, San Diego in January of 2009. Subjects faced 45 convex budget decisions. These 45 budgets involved nine combinations of starting times, $t$, and delay lengths, $k$, with annual interest rates that varied from zero to over 1,000 percent per year.

$\mathrm{A}(3 \times 3)$ design was implemented with three sooner payment dates, $t=(0,7,35)$ days from the experiment date, crossed with three delay lengths, $(k=35,70,98)$ days. ${ }^{10}$ Thus there are nine $(t, k)$ cells and within each cell are five CTB questions, generating 45 choices for each subject. We refer to each $(t, k)$ combination as a "choice set." The $t$ and $k$ combinations used in our study were selected to avoid holidays (including Valentine's Day), school vacations, spring break, and final

\footnotetext{
${ }^{9}$ Theoretically, extra-experimental interest rates and liquidity constraints should influence laboratory decisions (Coller and Williams 1999). If subjects can borrow (save) at rates inferior (superior) to the rates offered in the lab, then they have an arbitrage opportunity. If subjects are credit constrained, they may choose sooner experimental payments to smooth consumption. In a controlled experiment with MPLs, Coller and Williams (1999) show that providing external interest rate information and elaborating possible arbitrage strategies makes treated subjects appear only slightly more patient. Meier and Sprenger (2010) show that objectively measured credit constraints taken from individual credit reports are generally uncorrelated with MPL responses. For further discussion on arbitrage opportunities and liquidity constraints see online Appendix Section B.

${ }^{10}$ See below for the recruitment and payment efforts that allowed sooner payments, including those for $t=0$, to be implemented in the same manner as later payments.
} 
examination weeks. Payments were scheduled to arrive on the same day of the week ( $t$ and $k$ are both multiples of 7), to avoid differential weekday effects.

In each CTB question, subjects were given a budget of 100 tokens. Tokens allocated to sooner payments had a value of $a_{t}$ while tokens allocated to later payments had a value of $a_{t+k}$. In mest cases, $a_{t+k}$ was $\$ 0.20$ per token and $a_{t}$ varied from $\$ 0.20$ to $\$ 0.10$ per token. ${ }^{11}$ Note that $a_{t+k} / a_{t}=1+r$, the gross interest rate over $k$ days, so $(1+r)^{1 / k}$ gives the standardized daily interest rate. Daily net interest rates in the experiment varied considerably across the 45 budgets, from 0 to around 1 percent per day implying annual interest rates of between 0 and 1,300 percent (compounded quarterly).

Each choice set featured $a_{t+k}=\$ 0.20$ and $a_{t}=\$ 0.16(1+r=1.25)$. In eight of the nine choice sets, one convex budget represented a pure income shift relative to this choice. This was implemented with $a_{t+k}=\$ 0.25$ and $a_{t}=\$ 0.20(1+r=1.25$ again). In the remaining choice set, $(t, k)=(7,70)$, we instead implemented $a_{t}=\$ 0.20$ and $a_{t+k}=\$ 0.20$, a zero percent interest rate. Table 1 shows the token rates, interest rates, standardized daily interest rates, and corresponding annual interest rates for all 45 budgets.

\section{B. Implementation and Protocol}

One of the most challenging aspects of implementing any time discounting study is making all choices equivalent except for their timing. That is, transactions costs associated with receiving payments, including physical costs and confidence, must be equalized across all time periods. We took several unique steps in our subject recruitment process and payment procedures in order to closely equate transaction costs over time, which we discuss in the following subsections.

Recruitment.-In order to participate in the experiment, subjects were required to live on campus. All campus residents are provided with individual mailboxes at their dormitories. Students frequently use these mailboxes as all postal service mail and intra-campus mail are received at them. Each mailbox is locked and individuals have keyed access 24 hours per day.

By special arrangement with the university mail services office, we were granted same-day access to a specific subset of campus mailboxes, and subjects in our experiment were required to have been assigned one of these mailboxes. We recruited 97 undergraduate freshman and sophomores meeting these criteria.

Experimental Payments.-We employed six measures intended to equalize the costs of receiving payments. These measures not only attempt to equate transactions costs over sooner and later payments, but also to increase confidence that future payments will arrive. First, all sooner and later payments, including those for $t=0$, were placed in subjects' campus mailboxes. Subjects were fully informed of the

\footnotetext{
${ }^{11}$ In 8 of 45 choices, $a_{t+k}$ was $\$ 0.25$. If an individual allocated all her tokens in every choice to the later payment, she could expect to earn either $\$ 20$ or $\$ 25$. If she allocated all her tokens to the sooner payment in every choice, she would earn at least $\$ 10$.
} 
TABle 1 - Choice SeTS

\begin{tabular}{|c|c|c|c|c|c|c|c|}
\hline$t$ (start date $)$ & $k$ (delay) & Token budget & $a_{t}$ & $a_{t+k}$ & $(1+r)$ & $\begin{array}{l}\text { Daily rate } \\
\text { (percent) }\end{array}$ & $\begin{array}{c}\text { Annual rate } \\
\text { (percent) }\end{array}$ \\
\hline 0 & 35 & 100 & 0.19 & 0.2 & 1.05 & 0.147 & 65.3 \\
\hline 0 & 35 & 100 & 0.18 & 0.2 & 1.11 & 0.301 & 164.4 \\
\hline 0 & 35 & 100 & 0.16 & 0.2 & 1.25 & 0.64 & 528.9 \\
\hline 0 & 35 & 100 & 0.14 & 0.2 & 1.43 & 1.024 & $1,300.9$ \\
\hline 0 & 35 & 100 & 0.2 & 0.25 & 1.25 & 0.64 & 528.9 \\
\hline 0 & 70 & 100 & 0.19 & 0.2 & 1.05 & 0.073 & 29.6 \\
\hline 0 & 70 & 100 & 0.18 & 0.2 & 1.11 & 0.151 & 67.4 \\
\hline 0 & 70 & 100 & 0.16 & 0.2 & 1.25 & 0.319 & 178.1 \\
\hline 0 & 70 & 100 & 0.14 & 0.2 & 1.43 & 0.511 & 362.1 \\
\hline 0 & 70 & 100 & 0.2 & 0.25 & 1.25 & 0.319 & 178.1 \\
\hline 0 & 98 & 100 & 0.19 & 0.2 & 1.05 & 0.052 & 20.5 \\
\hline 0 & 98 & 100 & 0.16 & 0.2 & 1.25 & 0.228 & 113 \\
\hline 0 & 98 & 100 & 0.13 & 0.2 & 1.54 & 0.441 & 286.4 \\
\hline 0 & 98 & 100 & 0.1 & 0.2 & 2 & 0.71 & 637.1 \\
\hline 0 & 98 & 100 & 0.2 & 0.25 & 1.25 & 0.228 & 113 \\
\hline 7 & 35 & 100 & 0.19 & 0.2 & 1.05 & 0.147 & 65.3 \\
\hline 7 & 35 & 100 & 0.18 & 0.2 & 1.11 & 0.301 & 164.4 \\
\hline 7 & 35 & 100 & 0.16 & 0.2 & 1.25 & 0.64 & 528.9 \\
\hline 7 & 35 & 100 & 0.14 & 0.2 & 1.43 & 1.024 & $1,300.9$ \\
\hline 7 & 35 & 100 & 0.2 & 0.25 & 1.25 & 0.64 & 528.9 \\
\hline 7 & 70 & 100 & 0.2 & 0.2 & 1 & 0 & 0 \\
\hline 7 & 70 & 100 & 0.19 & 0.2 & 1.05 & 0.073 & 29.6 \\
\hline 7 & 70 & 100 & 0.18 & 0.2 & 1.11 & 0.151 & 67.4 \\
\hline 7 & 70 & 100 & 0.16 & 0.2 & 1.25 & 0.319 & 178.1 \\
\hline 7 & 70 & 100 & 0.14 & 0.2 & 1.43 & 0.511 & 362.1 \\
\hline 7 & 98 & 100 & 0.19 & 0.2 & 1.05 & 0.052 & 20.5 \\
\hline 7 & 98 & 100 & 0.16 & 0.2 & 1.25 & 0.228 & 113 \\
\hline 7 & 98 & 100 & 0.13 & 0.2 & 1.54 & 0.441 & 286.4 \\
\hline 7 & 98 & 100 & 0.1 & 0.2 & 2 & 0.71 & 637.1 \\
\hline 7 & 98 & 100 & 0.2 & 0.25 & 1.25 & 0.228 & 113 \\
\hline 35 & 35 & 100 & 0.19 & 0.2 & 1.05 & 0.147 & 65.3 \\
\hline 35 & 35 & 100 & 0.18 & 0.2 & 1.11 & 0.301 & 164.4 \\
\hline 35 & 35 & 100 & 0.16 & 0.2 & 1.25 & 0.64 & 528.9 \\
\hline 35 & 35 & 100 & 0.14 & 0.2 & 1.43 & 1.024 & $1,300.9$ \\
\hline 35 & 35 & 100 & 0.2 & 0.25 & 1.25 & 0.64 & 528.9 \\
\hline 35 & 70 & 100 & 0.19 & 0.2 & 1.05 & 0.073 & 29.6 \\
\hline 35 & 70 & 100 & 0.18 & 0.2 & 1.11 & 0.151 & 67.4 \\
\hline 35 & 70 & 100 & 0.16 & 0.2 & 1.25 & 0.319 & 178.1 \\
\hline 35 & 70 & 100 & 0.14 & 0.2 & 1.43 & 0.511 & 362.1 \\
\hline 35 & 70 & 100 & 0.2 & 0.25 & 1.25 & 0.319 & 178.1 \\
\hline 35 & 98 & 100 & 0.19 & 0.2 & 1.05 & 0.052 & 20.5 \\
\hline 35 & 98 & 100 & 0.16 & 0.2 & 1.25 & 0.228 & 113 \\
\hline 35 & 98 & 100 & 0.13 & 0.2 & 1.54 & 0.441 & 286.4 \\
\hline 35 & 98 & 100 & 0.1 & 0.2 & 2 & 0.71 & 637.1 \\
\hline 35 & 98 & 100 & 0.2 & 0.25 & 1.25 & 0.228 & 113 \\
\hline
\end{tabular}

payment method and the special arrangement made with university mail services. ${ }^{12}$ Eliminating in-lab payments ensures that subjects don't disproportionately prefer present in-lab payments because they are more likely to be received than future extra-lab payments. 
Second, upon beginning the experiment, subjects were told that they would receive a $\$ 10$ thank-you payment for participating. This $\$ 10$ was to be received in two payments: $\$ 5$ sooner and $\$ 5$ later, regardless of choices, and all experimental earnings were added to these two $\$ 5$ thank-you payments. This eliminated any convenience gained by concentrating payments in one period-two checks were sent regardless.

Third, two blank envelopes were provided to each subject. After receiving directions about the two thank-you payments, subjects were asked to address the envelopes to themselves at their campus mailbox, thus minimizing clerical errors on our part.

Fourth, at the end of the experiment, subjects were asked to write their payment amounts and dates on the inside flap of both envelopes, so they would see and verify the amounts written in their own handwriting when payments arrived, thus eliminating the cost of remembering the future amounts owed to them.

Fifth, one choice for each subject was selected for payment by drawing a numbered card at random. All experimental payments were made by personal check from Professor James Andreoni drawn on an account at the campus credit union. ${ }^{13}$ Individuals were informed that they could cash their checks (if they so desired) at this credit union, thus increasing the fidelity of the payment method.

Sixth, subjects were given the business card of Professor James Andreoni and told to call or e-mail him if a payment did not arrive and that a payment would be handdelivered immediately. This invitation to inconvenience a professor was intended to boost confidence that future payments would arrive as promised.

We believe that these efforts helped both equate transactions costs across payments, and engender experimenter trust. In an auxiliary survey, subjects were asked if they trusted that they would receive their experimental payments, and 97 percent of respondents replied yes.

Protocol.-A Java ${ }^{\mathrm{TM}}$-based client/server system was written to implement the CTB experiment. The server program sent budget information, recorded subject choices, and reported experiment earnings. The client program provided instructions to subjects, elicited choices, and administered a post-experiment questionnaire. Most importantly, the questionnaire asked subjects to calculate payoffs in a hypothetical situation and 97 percent were able to answer correctly.

Upon starting the experiment, subjects read through directions and CTB examples. The CTB examples indicated to subjects that tokens could be allocated entirely to the sooner payment, entirely to the later payment or divided between the two. The objective was not to lead subjects to interior or corner allocations with suggestive language. ${ }^{14}$ Screen shots of the instructions are presented in online Appendix E, which were read aloud and projected on a screen.

\footnotetext{
${ }^{13}$ Payment choice was guided by a separate survey of 249 undergraduate economics students eliciting payment preferences. Personal checks from Professor Andreoni, Amazon.com gift cards, PayPal transfers, and the university stored value system TritonCash were each compared to cash payments. Subjects were asked if they would prefer a $\$ 20$ payment made via each payment method or $\$ X$ cash, where $X$ was varied from 19 to 10 . Personal check payments were found to have the highest cash-equivalent value.

${ }^{14}$ Though we cannot be sure if the language led subjects toward or away from specific allocations, subjects were not shy about either type of allocation. Roughly 70 percent of responses are at corners, but only 36 of 97 subjects made zero interior allocations. See Section III for further detail.
} 


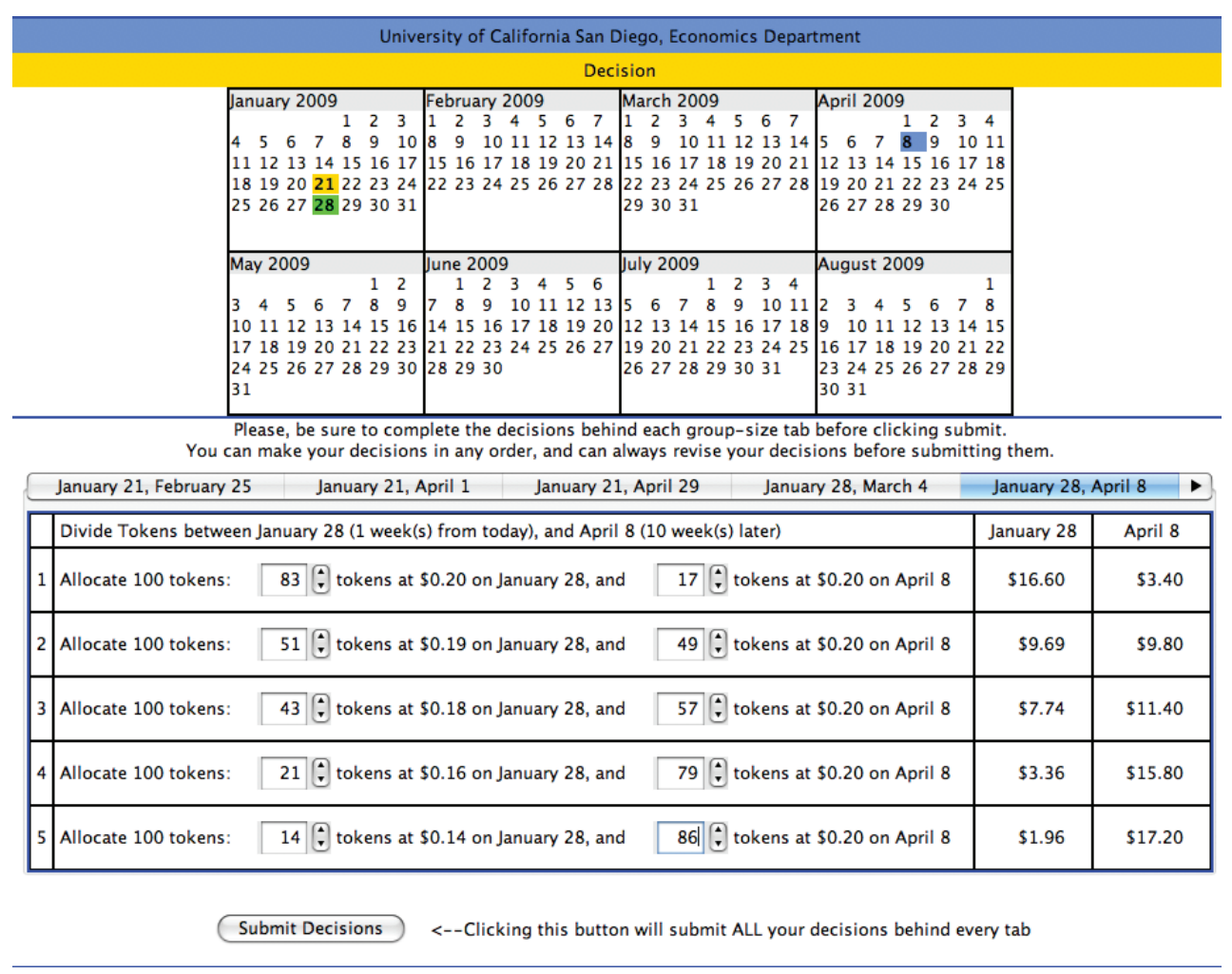

Figure 1. SAMPle Decision ScReEN

Subjects' decision screens displayed a dynamic calendar and a series of nine "decision tabs." These decision tabs corresponded to the nine choice sets described above, one tab for each $(t, k)$ combination. Subjects could respond to the decision tabs in any order they wished. Each decision tab had five budget decisions presented in order of increasing interest rate and then in order of increasing budget. ${ }^{15}$ An image of the decision screen is presented in Figure 1.

For each decision, individuals were told how many tokens they were to allocate (always 100), the sooner token value $a_{t}$, and the later token value $a_{t+k} \cdot{ }^{16}$ As each budget decision was being made, the calendar in the subjects' screen highlighted the experiment date (in yellow), the sooner date $t$ (in green), and the later date $t+k$ (in blue). This allowed subjects to visualize the delay length for a given decision. 17

\footnotetext{
${ }^{15}$ For a discussion of order effects and presenting choices by increasing interest rate, see Harrison et al. (2005).

${ }^{16}$ Individuals were not told the gross interest rate, $(1+r)$. However, in a companion questionnaire individuals were asked several numeracy questions, including one on compound interest. Roughly 70 percent of respondents were able to correctly answer a standard compound interest question. The level of numeracy in the sample suggests that the majority would be able to calculate at least the interest rate over the delay, $k$.

${ }^{17}$ Because $t$ and $k$ were multiples of 7 , all dates were described by the number of weeks (e.g., $t=7, k=35$ was described as "1 week from today" and " 5 weeks later"). Note, also, that allocation amounts were initially blank on the decision screen and subjects used up and down arrows to make choices.
} 
Background Consumption and DMPL.-In addition to the CTB experiment, we implemented a series of three MPLs and two HL risk price list tasks (the components of the DMPL). The MPLs featured the $(t, k)$ combinations: $(t=0, k=35)$, $(t=0, k=98),(t=35, k=35)$. The MPLs can be used to create alternate measures of both discounting and present bias for comparison. The HL risk price lists were designed to elicit risk aversion or utility function curvature over $\$ 20$ and $\$ 25$, respectively. 18

At the end of the computer-based CTB experiment, subjects were administered a questionnaire. Importantly, subjects were asked how much they spend in a typical week. The average response was $\$ 49.32$ per week or $\$ 7.05$ per day of "background consumption." This figure is used later in our analysis (see Section IIIB).

\section{Parameter Estimation with the CTB}

Given assumptions on the functional form of utility and the nature of discounting, the CTB provides a natural context in which to jointly estimate (and test hypotheses of) time preferences, present bias, and curvature of the utility function. To begin, we posit a time separable CRRA utility function discounted via the quasi-hyperbolic $\beta-\delta$ discounting function (Strotz 1956; Phelps and Pollak 1968; Laibson 1997),

$$
U\left(c_{t}, c_{t+k}\right)=\frac{1}{\alpha}\left(c_{t}-\omega_{1}\right)^{\alpha}+\beta \delta^{k} \frac{1}{\alpha}\left(c_{t+k}-\omega_{2}\right)^{\alpha},
$$

where $\delta$ is the one period discount factor and $\beta$ is the present bias parameter. The quasi-hyperbolic form elegantly captures the notion of present-biased time preferences and nests the exponential discounting when $\beta=1$. A value $\beta<1$ indicates present bias and when $t>0$ present bias does not influence choice. The values $c_{t}$ and $c_{t+k}$ are experimental earnings and $\alpha$ is the CRRA curvature parameter. ${ }^{19}$ The CRRA utility function is frequently estimated in experimental studies on both time and risk preferences and also used as the benchmark utility formulation across many fields of economics. The terms $\omega_{1}$ and $\omega_{2}$ are additional utility parameters which could be interpreted as classic Stone-Geary consumption minima, intertemporal reference points, or background consumption. For example, such utility parameters are used in Andersen et al. (2008), where experimental earnings are added to background consumption, $B$, such that $\omega_{1}=\omega_{2}=-B$. The parameter, $B$, is not estimated in their specification, but set to 118 Danish Kroner, the average value of daily consumption in Denmark in 2003, around US \$25 in 2009. Online Appendix Table A2 provides comparisons using various given values of $\omega_{1}$ and $\omega_{2}$.

Maximizing (3) subject to the future value budget (2) yields the tangency condition

$$
\frac{c_{t}-\omega_{1}}{c_{t+k}-\omega_{2}}=\left\{\begin{array}{ll}
\left(\beta \delta^{k}(1+r)\right)^{\left(\frac{1}{\alpha-1}\right)} & \text { if } t=0 \\
\left(\delta^{k}(1+r)\right)^{\left(\frac{1}{\alpha-1}\right)} & \text { if } t>0
\end{array}\right\},
$$

\footnotetext{
${ }^{18}$ The MPLs and HLs could also be chosen at random for payment. For directions and the price list tasks see online Appendix Section E2.

${ }^{19}$ The CRRA utility function is at times formulated as $c^{1-\theta} / 1-\theta$, with $\theta$ being the coefficient of relative risk aversion. This is equivalent to our utility formulation with $\theta=1-\alpha$.
} 
and the intertemporal formulation of a Stone-Geary linear demand for $c_{t}$,

$$
c_{t}=\left\{\begin{array}{ll}
{\left[\frac{1}{1+(1+r)\left(\beta \delta^{k}(1+r)\right)^{\left(\frac{1}{\alpha-1}\right)}}\right] \omega_{1}+\left[\frac{\left(\beta \delta^{k}(1+r)\right)^{\left(\frac{1}{\alpha-1}\right)}}{1+(1+r)\left(\beta \delta^{k}(1+r)\right)^{\left(\frac{1}{\alpha-1}\right)}}\right]\left(m-\omega_{2}\right)} & \text { if } t=0 \\
{\left[\frac{1}{1+(1+r)\left(\delta^{k}(1+r)\right)^{\left(\frac{1}{\alpha-1}\right)}}\right] \omega_{1}+\left[\frac{\left(\delta^{k}(1+r)\right)^{\left(\frac{1}{\alpha-1}\right)}}{1+(1+r)\left(\delta^{k}(1+r)\right)^{\left(\frac{1}{\alpha-1}\right)}}\right]\left(m-\omega_{2}\right)} & \text { if } t>0
\end{array}\right\} .
$$

\section{A. Estimation of Intertemporal Preferences}

Notice the parameters $(\beta, \delta, \alpha)$ and the data $(r, k, t)$ enter into the tangency condition of (4) and the demand function of (5) in a nonlinear fashion. Naturally, if $\alpha=1$, only corner solutions are obtained. We discuss estimation of the parameters $\beta, \delta, \alpha, \omega_{1}$, and $\omega_{2}$ when $\alpha<1$, and recognize that corner solutions may indeed arise in the data. ${ }^{20}$ We motivate two regression techniques, each with their benefits and weaknesses.

The first technique estimates (5) and the parameters $\beta, \delta, \alpha, \omega_{1}$, and $\omega_{2}$ using nonlinear least squares. Online Appendix Section A1 provides the details of the estimator. The strength of this methodology is that it estimates the Stone-Geary parameters $\omega_{1}$ and $\omega_{2}$. Its weakness is that it cannot account for the censored data issues inherent to potential corner solutions without additional distributional assumptions. ${ }^{21}$

For the second technique, we consider the tangency condition of (4). If we assume $\omega_{1}$ and $\omega_{2}$ are (nonestimated) known values, we can take logs to obtain

$$
\ln \left(\frac{c_{t}-\omega_{1}}{c_{t}+k-\omega_{2}}\right)=\left\{\begin{array}{ll}
\left(\frac{\ln \beta}{\alpha-1}\right)+\left(\frac{\ln \delta}{\alpha-1}\right) \cdot k+\left(\frac{1}{\alpha-1}\right) \cdot \ln (1+r) & \text { if } t=0 \\
\left(\frac{\ln \delta}{\alpha-1}\right) \cdot k+\left(\frac{1}{\alpha-1}\right) \cdot \ln (1+r) & \text { if } t>0
\end{array}\right\},
$$

which is linear in the data, $k$ and $\ln (1+r)$, and reduces to

$$
\ln \left(\frac{c_{t}-\omega_{1}}{c_{t+k}-\omega_{2}}\right)=\left(\frac{\ln \beta}{\alpha-1}\right) \cdot \mathbf{1}_{t=0}+\left(\frac{\ln \delta}{\alpha-1}\right) \cdot k+\left(\frac{1}{\alpha-1}\right) \cdot \ln (1+r),
$$

where $\mathbf{1}_{t=0}$ is an indicator for the time period $t=0$. Given an additive error structure, such a linear equation is easily estimated, with parameter estimates for $\delta, \beta$,

\footnotetext{
${ }^{20}$ With the employed utility formulation and $\alpha<1$, corner solutions can be predicted provided $\omega_{1}$ and $\omega_{2}<0$. As discussed in Section III, corner solutions are frequent. Online Appendix Tables A6 and A7 provide individual estimates and demonstrate that for the motivated regression techniques, individuals with only corner solutions have estimated values of $\alpha=0.999$, while individuals with more interior solutions are estimated to have more utility function curvature. This gives support to the employed regression techniques for identifying utility function curvature and near linear preferences. Indeed, estimated curvature is found to correlate strongly with the discussed bias in MPL-based discounting estimates. See Section IIIC for details.

${ }^{21}$ However, with such an assumption we could reduce the sum of squared residuals to the solution function (5) recognizing that $c_{t}$ will be censored in the interval $[0, m /(1+r)]$. Details of an NLS estimator of $(5)$ adapted for censoring are provided in online Appendix Section A1 and discussed in Section III. We thank an anonymous referee for this very helpful suggestion.
} 
and $\alpha$ obtained via nonlinear combinations of coefficient estimates. The weakness of estimation based on the tangency condition of (4) is that it requires first that the background parameters $\omega_{1}$ and $\omega_{2}$ be known, and second that the consumption ratio $\left(c_{t}-\omega_{1} / c_{t+k}-\omega_{2}\right)$ be strictly positive, such that the log transform is well-defined. The strength, however, is that censoring issues are easily addressed. Two-limit Tobit maximum likelihood regressions can be implemented to account for corner solutions (Wooldridge 2002). Online Appendix A2 provides details.

Of additional interest in the present analysis is robustness to alternate functional forms for utility. ${ }^{22}$ A leading alternative utility formulation, constant absolute risk aversion (CARA) utility is also easily estimable in the CTB environment. Indeed, because of the exponential form background parameters drop out of the marginal condition if $\omega_{1}=\omega_{2}$. The marginal condition can be written

$$
\exp \left(-\rho\left(c_{t}-c_{t+k}\right)\right)=\left\{\begin{array}{ll}
\beta \delta^{k} \cdot(1+r) & \text { if } t=0 \\
\delta^{k} \cdot(1+r) & \text { if } t>0
\end{array}\right\}
$$

where $\rho$ represents the coefficient of absolute risk aversion in the utility formulation $u\left(c_{t}\right)=-\exp \left(-\rho c_{t}\right)$. Taking logs and rearranging, this is linear in the data $1_{t=0}, k$, and $\ln (1+r)$, reducing to

$$
c_{t}-c_{t+k}=\left(\frac{\ln \beta}{-\rho}\right) \cdot \mathbf{1}_{t=0}+\left(\frac{\ln \delta}{-\rho}\right) \cdot k+\left(\frac{1}{-\rho}\right) \cdot \ln (1+r) .
$$

Both this tangency condition and the solution function,

(8) $c_{t}=\left(\frac{\ln \beta}{-\rho}\right) \cdot \frac{\mathbf{1}_{t=0}}{2+r}+\left(\frac{\ln \delta}{-\rho}\right) \cdot \frac{k}{2+r}+\left(\frac{1}{-\rho}\right) \cdot \frac{\ln (1+r)}{2+r}+\frac{m}{2+r}$,

can be easily estimated via similar Two-limit Tobit maximum likelihood regression techniques. Online Appendix A2 provides further detail. A CARA specification eliminates the need to estimate additional utility parameters and is easily handled with standard estimation techniques, but does not readily allow for comparison with prior CRRA estimates and different background assumptions. Given that each estimation strategy has its relative strengths, we provide all estimates and discuss any differences in our analysis.

\section{Experimental Results}

The results are presented in two subsections. First, we present aggregate CTB data and provide estimates of aggregate discounting, present bias, and curvature. Second, we explore individual level results, estimating preference parameters and comparing the results within-subject to parameters obtained from DMPL methodology. 


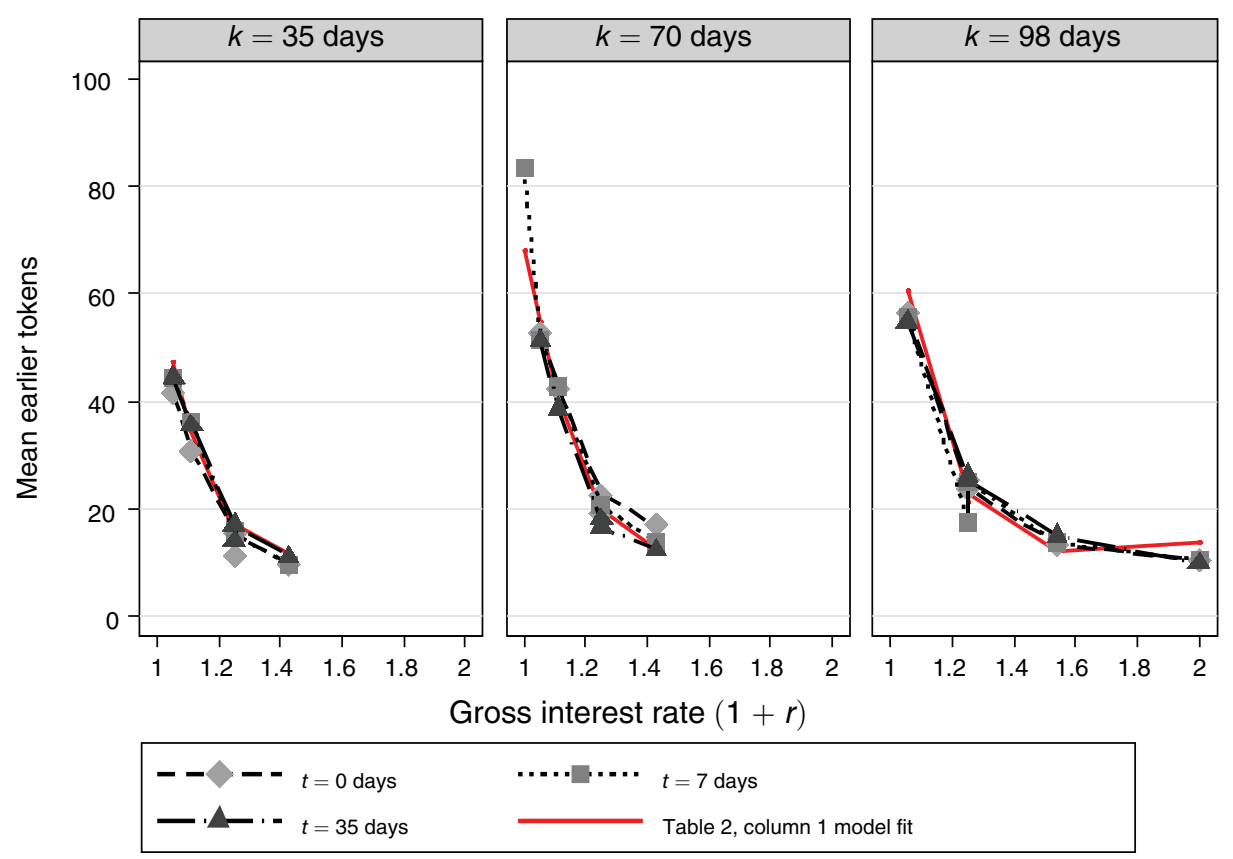

Figure 2. Mean Experimental Responses Over Time

\section{A. Aggregate Analysis}

We identify experimental allocations as solutions to standard intertemporal optimization problems. These solutions are functions of our parameters of interest (discounting and curvature), and experimentally varied parameters (interest rates and delay lengths). Our experimental results should mirror this functional relationship. In Figure 2 we plot the mean number of tokens chosen earlier against the gross interest rate, $(1+r)$, of each CTB decision. We plot separate points for the three experimental values of $t(t=0,7,35$ days), and separate graphs for the three experimental values of $k(k=35,70,98$ days $)$. At each delay length, the number of tokens allocated to the earlier payment declines monotonically with the interest rate; and at comparable gross interest rates, the number of tokens allocated earlier increases with delay.

Evidence for present bias or hyperbolic discounting would be observed in Figure 2 as the mean level of tokens allocated earlier being substantially higher when $t=0$ compared to $t=7$ or 35 . Instead, we observe that the mean number of earlier tokens at each interest rate is roughly constant across $t$.

Notice that Figure 2 also reveals that choices respond to both changing interest rates and delay lengths in a predicted way. ${ }^{23}$ Masked by these aggregate results, however, is important individual heterogeneity. Roughly 37 percent of subjects ( 36 of 97)

\footnotetext{
${ }^{23}$ Additionally, there is support for a homothetic utility function as the mean number of earlier tokens does not change appreciably with increased income.
} 
have no interior choices in 45 convex budgets, consistent with linear preferences. ${ }^{24}$ Additionally, for the remaining 61 subjects, in any given decision, an average of approximately 50 percent of responses are found at corners. In the following section we discuss estimation of aggregate preferences following the estimation procedures discussed in Section IIA that can and cannot account for such corner solutions. In Section IIIC, we discuss heterogeneity and provide individual estimates.

Before discussing parameter estimation, it is worthwhile to discuss the possibility of subject confusion and error in the new CTB environment. One common finding from standard MPL experiments is that 10-50 percent of subjects switch more than once in a given price list (Holt and Laury 2002; Meier and Sprenger 2010; Jacobson and Petrie 2009). We view such multiple switching as an extreme form of nonmonotonic demand. As the relative price decreases, tokens allocated to the sooner payment shifts from zero to 100 tokens and back again. Similar errors are more subtly revealed in the CTB environment as even minor nonmonotonicities can be identified and the law of demand can be tested. For example, in $(t=7, k=70)$ only 8 of 97 subjects had some nonmonotonicity, increasing demand of $c_{t}$ in response to an increased interest rate. To restore monotonicity for these eight subjects, one would need to adjust allocations by an average of 24.6 tokens with a future value of $\$ 4.93$. In an MPL, multiple switching would require adjustment of (at least) 100 tokens with a future value of $\$ 20$ to restore monotonicity. ${ }^{25}$

The CTB environment provides for the possibility of additional tests of subject errors and confusion beyond those of the standard MPL design. Our results indicate that CTB errors are small both in economic terms and relative to alternate designs. ${ }^{26}$ This provides a stable foundation for proceeding to parameter estimation based on the aggregate data.

Estimating Aggregate Preferences.-Table 2 presents estimates of aggregate preference parameters. In column 1 , the annual discount rate, present bias parameter, CRRA utility function curvature, and $\hat{\omega}_{1}$ and $\hat{\omega}_{2}$ are estimated by nonlinear least squares on solution function (5) with clustered standard errors.

Column 1 indicates, first, the aggregate annual discount rate is estimated at 0.300 (SE 0.064). This discount rate is lower than those estimated by most other researchers. ${ }^{27}$

\footnotetext{
${ }^{24}$ See online Appendix Tables A6 and A7 for individual censoring details and estimates.

${ }^{25}$ Only one subject required an adjustment of 100 tokens to restore demand monotonicity. Additional tests can be made for income monotonicity and positive discounting. Some subjects violate strict income monotonicity, by decreasing either $c_{t}$ or $c_{t+k}$ in response to an income increase. In eight experimental budget expansions, 72 of 97 subjects make two or fewer such monotonicity violations for $c_{t}$ and 89 of 97 subjects make two or fewer violations for $c_{t+k}$. Such violations may be a consequence of natural subject error as on average individuals would have to adjust their responses by only 1.67 later tokens (valued at $\$ 0.42$ ) to be consistent with income monotonicity. As well, there is support for positive discounting. For example, between the first, sixth, and eleventh budgets in Table 1, $(t=0, k=35,70,98),(1+r)=1.05$, only one subject strictly decreased her allocation to the earlier payment in response to the delay increase.

${ }^{26}$ Of course, in a convex decision environment, natural tests of the Weak Axiom of Revealed Preference should exist to examine whether the data can be rationalized by a utility function. Because our decision environment has no budget, intersections of these tests are not possible. Additionally, given the volume of corner solutions in the data, such tests may be difficult to design in general.

${ }^{27}$ Similar results are obtained when adapting the NLS criterion function for censoring. See online Appendix Table A1. Notable exceptions of similarly low discount rates include Coller and Williams (1999); Harrison, Lau, and Williams (2002); Harrison et al. (2005) which all assume linear preferences and Andersen et al. (2008), employing the DMPL technique.
} 
Table 2-Discounting and Curvature Parameter Estimates

\begin{tabular}{|c|c|c|c|c|c|c|c|c|}
\hline Method: & $\begin{array}{l}\text { NLS } \\
(1)\end{array}$ & $\begin{array}{l}\text { NLS } \\
(2)\end{array}$ & $\begin{array}{l}\text { NLS } \\
(3)\end{array}$ & $\begin{array}{l}\text { Tobit } \\
\text { (4) }\end{array}$ & $\begin{array}{l}\text { NLS } \\
(5)\end{array}$ & $\begin{array}{l}\text { Tobit } \\
(6)\end{array}$ & $\begin{array}{l}\text { Tobit } \\
(7)\end{array}$ & $\begin{array}{l}\text { Tobit } \\
(8)\end{array}$ \\
\hline Annual discount rate & $\begin{array}{c}0.300 \\
(0.064)\end{array}$ & $\begin{array}{c}0.377 \\
(0.087)\end{array}$ & $\begin{array}{c}0.371 \\
(0.091)\end{array}$ & $\begin{array}{c}0.324 \\
(0.173)\end{array}$ & $\begin{array}{c}0.246 \\
(0.128)\end{array}$ & $\begin{array}{c}0.275 \\
(0.162)\end{array}$ & $\begin{array}{c}0.254 \\
(0.159)\end{array}$ & $\begin{array}{c}0.335 \\
(0.136)\end{array}$ \\
\hline Present bias: $\hat{\beta}$ & $\begin{array}{c}1.004 \\
(0.002)\end{array}$ & $\begin{array}{c}1.006 \\
(0.006)\end{array}$ & $\begin{array}{c}1.007 \\
(0.006)\end{array}$ & $\begin{array}{c}1.023 \\
(0.010)\end{array}$ & $\begin{array}{c}1.026 \\
(0.008)\end{array}$ & $\begin{array}{c}1.026 \\
(0.010)\end{array}$ & $\begin{array}{c}1.028 \\
(0.010)\end{array}$ & $\begin{array}{c}1.017 \\
(0.008)\end{array}$ \\
\hline CRRA curvature: $\hat{\alpha}$ & $\begin{array}{c}0.920 \\
(0.006)\end{array}$ & $\begin{array}{c}0.921 \\
(0.006)\end{array}$ & $\begin{array}{c}0.897 \\
(0.009)\end{array}$ & $\begin{array}{c}0.977 \\
(0.004)\end{array}$ & $\begin{array}{c}0.706 \\
(0.017)\end{array}$ & $\begin{array}{c}0.873 \\
(0.018)\end{array}$ & & \\
\hline CARA curvature: $\hat{\rho}$ & & & & & & & $\begin{array}{c}0.008 \\
(0.001)\end{array}$ & $\begin{array}{c}0.007 \\
(0.001)\end{array}$ \\
\hline$\hat{\omega}_{1}$ & $\begin{array}{c}1.368 \\
(0.275)\end{array}$ & & & & & & & \\
\hline$\hat{\omega}_{2}$ & $\begin{array}{c}-0.085 \\
(1.581)\end{array}$ & & & & & & & \\
\hline$\hat{\omega}_{1}=\hat{\omega}_{2}$ & & $\begin{array}{c}1.350 \\
(0.278)\end{array}$ & ${ }^{0}$ & $\begin{array}{r}-0.01 \\
-\end{array}$ & $\begin{array}{c}-7.046 \\
-\end{array}$ & $\begin{array}{c}-7.046 \\
-\end{array}$ & - & - \\
\hline$R^{2} / \mathrm{LL}$ & 0.4911 & 0.4908 & 0.4871 & $-7,642.74$ & 0.4499 & $-5,277.56$ & -8.864 .52 & $-7,772.91$ \\
\hline Observations & 4,365 & 4,365 & 4,365 & 4,365 & 4,365 & 4,365 & 4,365 & 4,365 \\
\hline Uncensored & - & - & - & 1,329 & - & 1,329 & 1,329 & 1,329 \\
\hline Clusters & 97 & 97 & 97 & 97 & 97 & 97 & 97 & 97 \\
\hline
\end{tabular}

Notes: NLS and two-limit Tobit ML estimators. Column 1: Unrestricted CRRA regression of equation (5). Column 2: CRRA regression of equation (5) with restriction $\omega_{1}=\omega_{2}$. Columns 3 and 4: CRRA regressions of equations (5) and (4), respectively, with restriction $\omega_{1}=\omega_{2}=0$. Columns 5 and 6: CRRA regressions of equations (5) and (4), respectively, with restriction $\omega_{1}=\omega_{2}=-7.046$ (the negative of average reported daily spending). Columns 7 and 8: CARA regressions of equations (6) and (7), respectively. Clustered standard errors in parentheses. Annual discount rate calculated as $(1 / \hat{\delta})^{365}-1$. Standard errors calculated via the delta method.

Second, aggregate curvature is precisely estimated at $\hat{\alpha}=0.920(\mathrm{SE}=0.006)$, significantly different from $1\left(F_{1,96}=155.18, p<0.01\right)$, but far closer to linear utility than estimated from the DMPL approach employing HL risk measures or other experimental estimates of risk aversion. For comparison, using DMPL methodology with Danish subjects, Andersen et al. (2008) find a CRRA curvature parameter of 0.259 . When allowing for this curvature and setting both $\omega_{1}$ and $\omega_{2}$ equal to minus average daily spending in Denmark, Andersen et al. (2008) find a discount rate of 0.101 . When assuming linear utility, they obtain a discount rate of 0.251.

The third, and most prominent finding is that, echoing Figure 2, we find no evidence of present bias. That is, $\hat{\beta}$ is estimated to be $1.004(\mathrm{SE}=0.002)$. The hypothesis of no present bias, $\beta=1$, is marginally rejected $\left(F_{1,96}=2.82, p<0.10\right)$, with the favored alternative being future bias, $\beta>1$. Obtaining a precisely estimated $\hat{\beta}$ so close to 1 is of specific interest. The general finding in both monetary and nonmonetary experiments and aggregate analyses is of substantial present bias (Frederick, Loewenstein, and O'Donoghue 2002), with a suggested value for $\beta$ of around 0.7 (Laibson, Repetto, and Tobacman 2003). Figure 2 also provides model fits corresponding to Table 2 , column $1, t=35$ days, demonstrating that the estimated time consistent preferences closely fit the aggregate data. However, the $R^{2}$ value indicates that substantial variation remains unexplained, potentially related to individual heterogeneity. Individual analyses are presented in Section IIIC.

The finding of no aggregate present bias is at striking odds with a body of experimental results in both economics and psychology. Reconciling our findings with 
others is an important issue. A potential explanation is associated with our experimental methodology. First, experimental evidence suggests that present bias may be conflated with subjects' assessment of the risk of receiving payments (Halevy 2008). ${ }^{28}$ Keren and Roelofsma (1995) and Weber and Chapman (2005) find in two of three experiments that when applying increasing levels of risk to both present and future payments, present bias decreases to some degree. Our experimental methodology is designed to eliminate differential risk between sooner and later payments. Indeed, in Andreoni and Sprenger (2012b) we show that when differential payment risk is exogenously added back into the decision environment, a hyperbolic pattern of discounting appears.

While our methodology suggests that equalization of payment risks may explain our findings, other hypotheses exist. Principal among these hypotheses is that present bias is a visceral response only activated when sooner rewards are actually immediate. For example, dynamic inconsistency is shown to manifest itself in immediate choices over healthy and unhealthy snacks (Read and van Leeuwen 1998), juice drinks (McClure et al. 2007) and more immediate monetary rewards (McClure et al. 2004). ${ }^{29}$ In order to equate transaction costs over sooner and later payments we were unable to provide truly immediate rewards. Viewed in this light, our findings represent a potential bound on present bias. With delays of a few hours between decisions and rewards, present bias may have gone undetected. A second hypothesis is that monetary payments should perhaps not elicit present bias to the same extent as more tempting primary goods. Though the body of experimental evidence on present bias has used monetary payments, and high correlations are obtained across primary and monetary intertemporal rewards (Reuben, Sapienza, and Zingales 2010), the underlying psychological models are very clearly focused on the temptation of consumption utility and not on monetary rewards (Laibson 1997; O’Donoghue and Rabin 1999; Gul and Pesendorfer 2001). A third hypothesis is that unstudied elements of the CTB presentation encourage dynamic consistency. We explore this possibility in Section IIIC by comparing CTB present bias with MPL present bias. MPL-identified present bias is substantially lower than previously obtained and correlates significantly with that found in CTBs at the individual level, suggesting that aspects of payment mechanism and not CTB presentation are most likely responsible for the limited present bias in our context. It must also be recognized that our findings are one study among many, and clearly further research is necessary before firm conclusions can be drawn.

\section{B. Robustness to Background Consumption and Utility Forms}

Extra-experimental consumption poses an important challenge for studies of time preferences. While experimenters are able to vary experimental payments, subjects make choices over consumption streams including both experimental payments and nonexperimental consumption. It is assumed that individuals do not adjust their

\footnotetext{
${ }^{28}$ Indeed, this is the motivating argument for experimental front-end delays. See, for example, Harrison, Lau, and Williams (2002); Harrison et al. (2005).

${ }^{29}$ In McClure et al. (2004), immediate monetary rewards were received via e-mail in the form of Amazon gift certificates directly after the experiment.
} 
nonexperimental consumption. That is, $\omega_{1}$ and $\omega_{2}$ are taken as nonestimated, fixed parameters. Prior research has set these to zero or fixed $-\omega_{1}$ and $-\omega_{2}$ to match the average value of daily consumption (Andersen et al. 2008).

In column 1 of Table 2, we report estimates of both Stone-Geary parameters $\hat{\omega}_{1}$ and $\hat{\omega}_{2}$. The hypothesis that $\omega_{1}=\omega_{2}$ is not rejected $\left(F_{1,96}=0.87, p=0.35\right)$. In column 2 we report estimates of an identical NLS procedure with the restriction that $\omega_{1}=\omega_{2}$ and obtain very similar results. This suggests the restriction that $\omega_{1}=\omega_{2}$ is not costly.

Columns 3 through 6 of Table 2 examine whether the results are influenced by procedures that fix rather than estimate $\omega_{1}$ and $\omega_{2}$. Additionally, fixed values of $\omega_{1}$ and $\omega_{2}$ allow us to easily compare results across the estimators motivated in Section IIA. We estimate nonlinear least squares regressions identical to columns 1 and 2 and impose varying restrictions on the values of $\omega_{1}$ and $\omega_{2}$. We also provide two-limit Tobit maximum likelihood regressions accounting for corner solution censoring, corresponding to the same restrictions.

In columns 3 and 4 , the imposed restriction is $\omega_{1}=\omega_{2}=0.30$ In columns 5 and 6 , we restrict $\omega_{1}=\omega_{2}=-7.05$, based on a post-experiment questionnaire which elicited average daily consumption of our subjects to be $\$ 7.05$.

Some differences in estimated parameters are obtained across econometric techniques. In particular, curvature is less pronounced when accounting for the censored nature of the data, as should be expected. Across econometric techniques, estimated preference parameters are found to be sensitive to the choice of background parameters. Both the estimated discount rate and $\hat{\alpha}$ decrease appreciably as the restricted value of the $\omega$ parameters moves from 0 to -7.05 . The present bias parameter $\hat{\beta}$ varies in a tight range. ${ }^{31}$ These results suggest that the method of determining the $\omega$ parameters is potentially of great relevance. In online Appendix Table A2, we demonstrate the effect of changing the values of $\omega_{1}$ and $\omega_{2}$ on estimated preference parameters for both NLS and Tobit estimators. The results indicate substantial sensitivity of estimated parameters (particularly curvature) to increasingly negative values of $\omega_{1}$ and $\omega_{2}$. Corresponding $R^{2}$ and likelihood values diminish accordingly.

Understanding the sensitivity of curvature parameter estimates to differing background assumptions is important as it speaks to the identifiability of the background terms separately from utility function curvature. As is clear from the log tangency condition (6), curvature is identified from the sensitivity of the background-adjusted consumption ratio, $\ln \left(\left(c_{t}-\omega_{1}\right) /\left(c_{t+k}-\omega_{2}\right)\right)$, to changes in interest rates, $\ln (1+r)$, while discounting is identified from the relative sensitivity of $\ln \left(\left(c_{t}-\omega_{1}\right) /\left(c_{t+k}-\omega_{2}\right)\right)$ to changes in both interest rates and delay lengths, $k$. Smaller changes in $\ln \left(\left(c_{t}-\omega_{1}\right) /\left(c_{t+k}-\omega_{2}\right)\right)$ in response to interest rate changes are associated with more pronounced utility function curvature. Of course, if the $\omega$ terms take large negative values, then $\ln \left(\left(c_{t}-\omega_{1}\right) /\left(c_{t+k}-\omega_{2}\right)\right)$ varies in a tight range around 0 , suggesting more curvature. The logic can be seen within a single choice. Consider an individual who allocates her entire budget to the sooner payment,

\footnotetext{
${ }^{30}$ In column 4 , the restriction is $\omega_{1}=\omega_{2}=-0.01$, such that the $\log$ consumption ratio $\ln \left(c_{t}-\omega_{1} / c_{t+k}-\omega_{2}\right)$ is well-defined.

${ }^{31}$ Similar results are obtained when adapting the NLS criterion function for censoring. See online Appendix Table A1.
} 
yielding $\$ X$ in earlier experimental payments. Under the assumption $\omega_{1}=\omega_{2}=0$, the individual's two period consumption stream is $(X, 0)$, suggesting no desire to smooth consumption (i.e., linear utility). Under the assumption $\omega_{1}=\omega_{2}=-10 X$, the individual's two period consumption stream is $(11 X, 10 X)$, a smoother stream suggesting substantially more utility function curvature. Likewise, one can fix this same allocation and two levels of curvature, generating different conclusions as to background consumption. A similar argument can be made for discounting. ${ }^{32}$

Given the above challenges, it is helpful to consider alternate functional forms. As discussed in Section IIA, background parameters are eliminated from estimation under CARA utility if $\omega_{1}=\omega_{2}$. In columns 7 and 8 of Table 2 we provide two-limit Tobit CARA estimates based on equations (7) and (8). Virtually identical discounting and present bias parameters are estimated under this alternative functional form. The coefficients of absolute risk aversion of $\hat{\rho}$ between 0.007 and 0.008 again indicate limited utility function curvature estimated from CTB responses. Taken as a measure of risk aversion, for a 50-50 gamble over \$20 and \$0, our CARA column 7 and CRRA column 3 estimates predict certainty equivalents of $\$ 9.60$ and $\$ 9.23$, respectively. These values are far from the often-found extreme small-stakes risk aversion and require further research on the relationship between risk and time preferences. This work is begun in Andreoni and Sprenger (2012b).

\section{Individual Analysis}

Table 3 presents estimates of discounting, present bias, and curvature parameters at the individual level. For each subject, we estimate the parameters of equation (5). To limit the number of estimated parameters and facilitate comparison with DMPL methodology, we restrict $\omega_{1}=\omega_{2}=0$. The parameters $\hat{\beta}, \hat{\delta}$, and CRRA curvature parameter, $\hat{\alpha}$, are estimated by nonlinear least squares as in Table 2, column 3. ${ }^{33}$ As robustness tests we first conduct estimation restricting $\omega_{1}=\omega_{2}$ at various levels and, second, we allow $\omega_{1}$ and $\omega_{2}$ to equal minus self-reported daily consumption. Additionally, we provide Tobit and OLS estimates. Obtained values are similar to Table 3 and reported in online Appendix Tables A3 through A5.

Time preferences and curvature parameters are estimable for 86 of 97 subjects. ${ }^{34}$ The results are broadly consistent with those estimated at the aggregate level. The median estimated annual discount rate is 0.41 , close to the aggregate values obtained in Table 2. Echoing the aggregate results, individual present bias is limited as the median

\footnotetext{
${ }^{32}$ Consider an individual who makes the same experimental choice as above, but at a slightly higher interest rate instead chooses to allocate her entire budget to the later payment yielding $\$ Y>\$ X$ in later experimental payments. For a small enough change in interest rate, $u\left(X-\omega_{1}\right) \approx \delta \times u\left(Y-\omega_{2}\right)$. For simplicity, assume linear utility (the argument is maintained for any fixed level of curvature). Under the assumption $\omega_{1}=\omega_{2}=0, \delta \approx X / Y$. Under the assumption $\omega_{1}=\omega_{2}=-10 X, \delta \approx 11 X /(Y+10 X)$. The estimated discount factor will be higher and corresponding discount rate will be lower under the second assumption.

${ }^{33}$ We opted for the NLS estimator to accommodate the restriction $\omega_{1}=\omega_{2}=0$. Additionally, the Tobit estimators require a sufficient number of noncensored interior solutions for estimation. Given that 36 of 97 subjects have no interior solutions, consistent with linear preferences, this condition would not be met for a number of experimental subjects. See online Appendix A2 for details.

${ }^{34}$ We do not study the 11 remaining subjects. Eight of these subjects had zero variance in their experimental responses, allocating the same number of sooner tokens in each choice set. Estimation convergence is not achieved for two subjects and the last remaining subject gave an identical pattern of sooner token choices in every choice set: 4 tokens in the first decision, 3 in the second, 2 in the third, 1 in the fourth, and 0 in the fifth.
} 
Table 3-Individual Discounting, Present Bias, and Curvature Parameter Estimates

\begin{tabular}{lcccrrr}
\hline \hline & $N$ & Median & $\begin{array}{c}5 \text { th } \\
\text { Percentile }\end{array}$ & $\begin{array}{c}\text { 95th } \\
\text { Percentile }\end{array}$ & Min & Max \\
\hline Annual discount rate & 86 & 0.4076 & -0.1784 & 5.618 & -0.9949 & 35.3555 \\
Daily discount factor: $\hat{\delta}$ & 86 & 0.9991 & 0.9948 & 1.0005 & 0.9902 & 1.0146 \\
Present bias: $\hat{\beta}$ & 86 & 1.0011 & 0.9121 & 1.1075 & 0.7681 & 1.3241 \\
CRRA Curvature: $\hat{\alpha}$ & 86 & 0.9665 & 0.7076 & 0.9997 & -0.1331 & 0.9998 \\
\hline
\end{tabular}

Note: NLS estimators with restriction $\omega_{1}=\omega_{2}=0$, as in Table 2, column 3 .

estimated $\hat{\beta}$ is 1.001 . The median estimated $\hat{\alpha}$ is 0.967 , suggesting that individual curvature, like aggregate curvature, is limited. In addition to median values, Table 3 reports the fifth to ninety-fifth percentile range for individual estimates of the annual discount rate, $\hat{\delta}, \hat{\beta}$, and $\hat{\alpha}$ along with the minimum and maximum values estimated. For the majority of subjects, the employed estimation strategy generates reasonable parameter estimates. However, extreme observations do exist. Figure 3, panel A presents histograms of individual curvature and discounting estimates from the CTB methodology. The histograms demonstrate that a large proportion of subjects have low discount rates, limited present bias and limited utility function curvature. Estimation results for all subjects are in online Appendix Tables A6 and A7.

Correlation Between CTB Parameter Estimates and DMPL Calculations.-For completeness, we compare individual discounting and curvature parameter estimates from the CTB to those calculated from DMPL methodology. Three standard time multiple price lists and two HL risk price lists were administered to all subjects. From the three price lists, we calculate daily discount factors following standard practice. ${ }^{35}$ Given a switching point, $X$, a later payment, $Y$, and a delay length, $k$, in a price list, $l$, we calculate the daily discount factor as $d_{l}=(X / Y)^{1 / k}$. This is equivalent to positing a linear utility function and background $\omega_{1}=\omega_{2}=0$. We examine the average of the three measures, $d=1 / 3 \cdot\left(d_{1}+d_{2}+d_{3}\right)$. From the two HL risk price lists, we calculate curvature parameters also following standard practice. ${ }^{36}$ Given a switching probability pair, $(p, 1-p)$, and two HL lotteries, $A$ and $B$, in a specific price list $l$ we take the value $a_{l}$ that equates the CRRA expected utility of lottery A and lottery B. We take the midpoint of the interval in which this value lies as the calculated curvature parameter, $a_{l}$. We examine the average value, $a=1 / 2 \cdot\left(a_{1}+a_{2}\right)$. In both MPLs and HLs, individuals must exhibit a unique switching point to have a calculable discount factor or curvature parameter.

Of the subjects for whom we estimate $\hat{\delta}, 84$ of 86 have a calculable discount factor, $d$. The median value implies an annual discount rate of 137 percent, which replicates the very high observed discount rates in MPL experiments assuming linear utility. Of

\footnotetext{
${ }^{35}$ MPL switch points yield an interval of the individual discount factor (Coller and Williams 1999), which is easily accounted for with interval regression techniques (Coller and Williams 1999; Harrison, Lau, and Williams 2002). However, common practice for calculation takes one point in the interval (see, for example, Ashraf, Karlan, and Yin 2006; Burks et al. 2009; Meier and Sprenger 2010). We choose the point of the interval that makes subjects appear the most patient.

${ }^{36} \mathrm{HL}$ switch points yield an interval of the individual curvature parameter (Holt and Laury 2002), which can be accounted for with either interval regression techniques or alternative estimators (Harrison et al. 2005). However, common practice for calculation takes one point in the interval or alternatively the number of lottery A choices (see, for example, Dohmen et al. 2005; Holt and Laury 2002).
} 

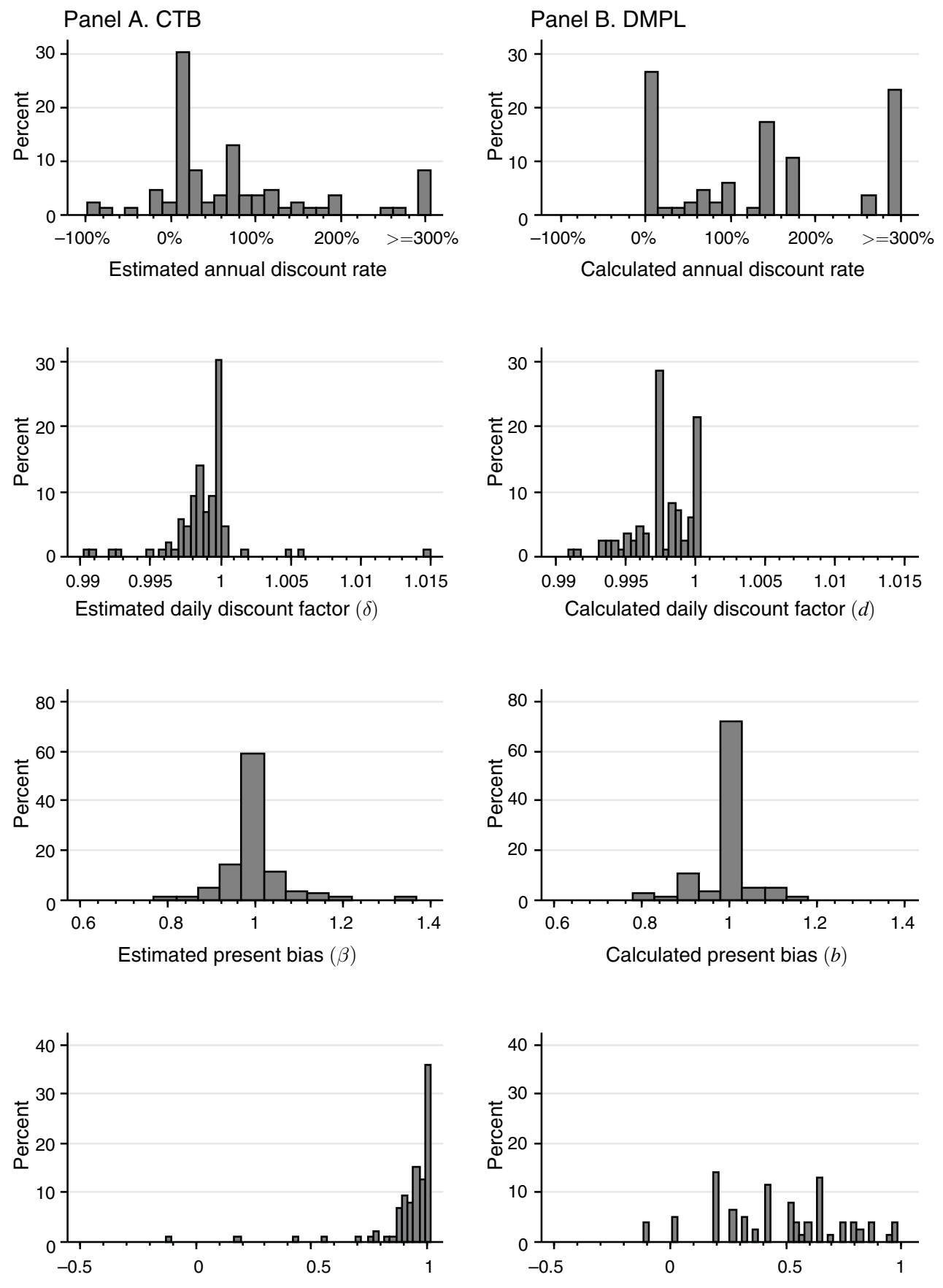

Estimated curvature parameter $(\alpha)$

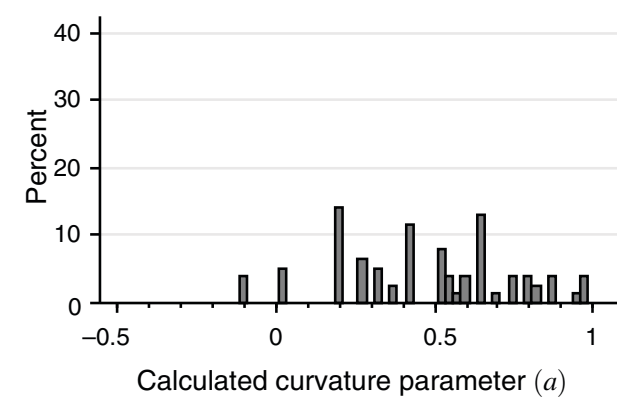

Figure 3. Histograms of CTB Estimates and DMPL Calculations 
the subjects for whom we estimate $\hat{\alpha}, 77$ of 86 have a calculable curvature parameter, $a$. The median value is 0.513 indicating substantial utility curvature.

We can also identify present bias in the MPLs by the standard methodology of comparing the $(t, k)=(0,35)$ MPL to the $(t, k)=(35,35)$ MPL. Fourteen of 84 subjects $(16.7$ percent $)$ are classified as present-biased, $\left(d_{(t=0, k=35)}<d_{(t=35, k=35)}\right)$, while the median present bias parameter, $b$, is $1 .{ }^{37}$ For comparison, using similar MPL methods, Ashraf, Karlan, and Yin (2006), and Meier and Sprenger (2010) find around 30-35 percent of subjects to be present-biased and a substantially smaller percentage to be future-biased. In contrast, using closely controlled payments and the CTB method, Giné et al. (2010) find limited aggregate present bias and almost equal appearances of present and future bias. ${ }^{38}$ This further supports the notion that our unique payment methods resulted in fewer instances of apparent present bias.

Figure 3, panel B provides histograms of these calculations for comparison with CTB estimates. Figure 3 shows that present bias is found to be similar across elicitation techniques. Discount rates and curvature, however, differ substantially. Time and risk price lists yield systematically higher discount rates and utility function curvature than CTB estimates. As in Andersen et al. (2008), correcting for curvature from the HL risk measures yields lower discounting estimates. Performing such an exercise, we obtain a median discount rate estimate of 33 percent per year. However, such a correction may be misguided given the wide difference between HL risk measures and the CTB estimates. This motivates careful examination of the correlation of obtained preference parameters across elicitation methods.

Figure 4 plots calculated DMPL and estimated CTB parameters against each other. In panel A the calculated discount factor, $d$, is plotted against the estimated parameter, $\hat{\delta}$, along with an estimated regression line and 45 degree line. Panel B is similar for $a$ and $\hat{\alpha}$. No panel is presented for $b$ and $\beta$, because of the sheer volume of responses near to $(b, \hat{\beta})=(1,1)$. However, estimated present bias from CTB methodology, $\hat{\beta}$, and calculated present bias from MPL methodology $b$ are significantly correlated $(\rho=0.255, p<0.05)$ as are $\hat{\beta}$ and the frequently-used categorical variable classifying present-biased (1), dynamically consistent (0) and future biased $(-1)$ subjects, $(\rho=-0.274, p<0.05)$. The correlation between DMPL and CTB present bias further suggests that payment methods as opposed to CTB presentation led to less apparent present bias.

Panel A of Figure 4 shows a high degree of correlation between MPL calculated and CTB estimated discount factors $(\rho=0.420, p<0.001)$. However, most of the data lies above the 45 degree line, consistent with standard arguments that, under concave utility, discount factors calculated from price lists alone will be downwardbiased. Additionally, we can examine the difference, $\hat{\delta}-d$, as a measure of price list-induced bias. Interestingly, this discounting bias measure is negatively correlated with CTB estimated curvature, $\hat{\alpha},(\rho=-0.743, p<0.001)$. Subjects who are closer to linear utility will have less biased MPL-calculated discount factors. This indicates that, though biased, standard MPLs do yield useful measures of time

\footnotetext{
${ }^{37}$ Present bias $b$ is calculated as $\left(d_{(t=0, k=35)} / d_{(t=35, k=35)}\right)^{35}$. Nine subjects are classified as future-biased $\left(d_{(t=0, k=35)}>d_{(t=35, k=35)}\right)$ and 61 are classified as dynamically consistent $\left(d_{(t=0, k=35)}=d_{(t=35, k=35)}\right)$.

${ }^{38}$ Additionally, Giné et al. (2010) allow individuals to revise prior choices. Present bias, as measured in CTBs, predicts present-biased revisions. This gives support to the CTB methodology for being able to both measure individual preferences and predict important choice.
} 
Panel A. Daily discount factors

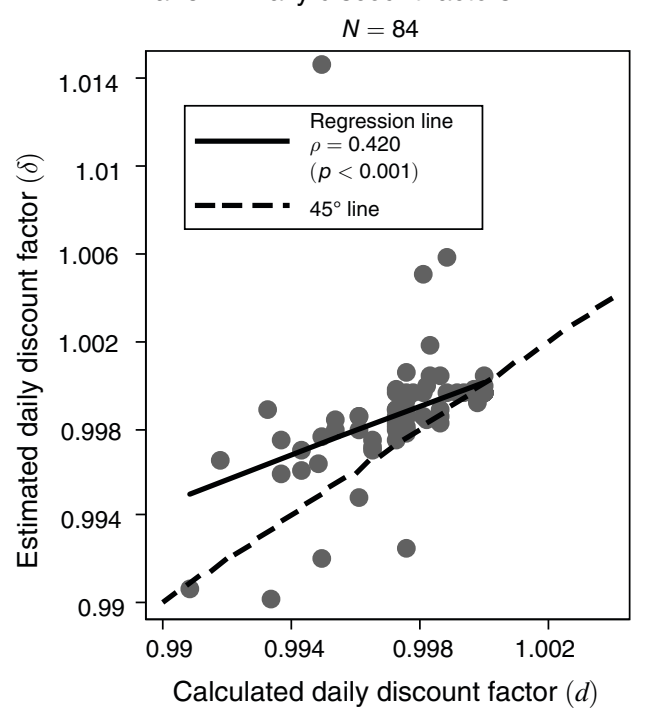

Panel B. Curvature parameters

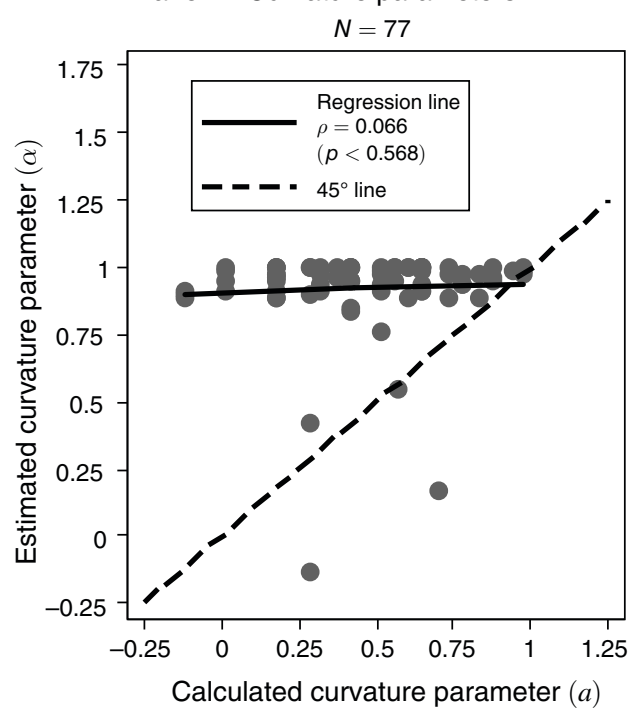

Figure 4. Comparison of CTB Estimates and DMPL Calculations

preference and that the bias attenuates with utility function curvature as theoretically predicted. Importantly, HL measured curvature does not correlate with the bias $(\rho=-0.092, p=0.431)$.

The lack of correlation between HL curvature and price list-induced discounting bias is not surprising. It is generated by the apparent zero correlation in panel B of Figure 4 between HL calculated curvature, $a$, and CTB estimated curvature $\hat{\alpha}$ ( $\rho=0.066, p=0.568$ ). This is interesting because, under CRRA utility, the two elicitation methodologies ostensibly measure the same utility construct. Not only is the level of curvature inconsistent between the two, but also the correlation is remarkably low. Additionally, HL curvature cannot account for the bias induced in MPL discounting experiments. These findings suggest that the practice of using HL risk experiments to identify and correct for curvature in discounting may be problematic.

As we obtain different parameter estimates across CTB and DMPL methodologies, a natural question arises as to which is better for eliciting time preferences. Though the individual analyses suggest the CTB estimates are more reasonable and can better explain the curvature-induced bias in MPL discount factors, more research must be conducted before firm conclusions can be drawn. Additionally, recent work from Noor $(2009,2011)$ demonstrates that an alternate experimental methodology fixing monetary payments and having delay length be the object of choice can, under certain regularity conditions, elicit discounting functions. This is in contrast to most experimental designs such as both CTB and MPL where timedated rewards, with varying delay lengths and monetary values, are the object of choice. Though this new methodology has not been widely implemented, it should be tested and related to both CTB and DMPL techniques in order to both better understand the new mechanism and potentially understand which of the common time-dated rewards methodologies yields more consistent measures. 


\section{Conclusion}

MPLs and other experimental methods frequently produce high estimates of annual discount rates at odds with nonlaboratory measures. A possible bias of MPLs is the imposition of linear preferences, generating upward-biased discount rate estimates if utility is actually concave. Solutions to this bias to date have relied on Double Multiple Price List methodology: identifying time preferences with MPLs and utility function curvature with HL risk measures.

We propose a single simple instrument that identifies discounting and utility function curvature, that we call Convex Time Budgets. Allocations in Convex Time Budgets are viewed as solutions to standard intertemporal optimization problems with convex choice sets. Given assumptions on functional form, discounting and curvature parameters are estimable. Additionally, tests of present-biased time preferences are easily implemented.

In a computer-based experiment with 97 subjects, we show that CTBs precisely identify discounting and curvature parameters at both the aggregate and individual levels. Across specifications, we find an aggregate discount rate of around 30 percent per year, substantially lower than most experimental estimates. Linear utility is rejected econometrically, though we find less utility function curvature than obtained with DMPL methodology or most studies using HL risk measures. Additionally, we find no evidence of present bias.

When examining individual estimates, we find that MPL-elicited discount rates, though upward-biased, do correlate with CTB estimates. HL risk measures, however, are found to be virtually uncorrelated with CTB estimated utility function curvature.

These findings raise several natural and important questions. First, why did we find no evidence of present bias, while so many other studies using cash rewards do find present bias? The most likely answer, it appears to us, lies in the unique steps we took to equate the costs and risks associated with sooner and later payments. This is surely the most consequential aspect of our findings, and as such invites rigorous replication and testing.

Second, why do we find substantial differences between CTB estimates and those obtained with DMPL methodology? In particular, why is the curvature over time obtained from CTBs so different from and uncorrelated with the curvature over risk obtained from HL measures. Why can't HL risk measures account for MPL-induced bias in discounting? At a minimum, these results indicate that using risk experiments to identify curvature in discounting may be problematic.

Together, these two points suggest that future research is necessary on the interactions between risk and time. Particular attention should be given to investigating the link between payment risk and present bias. One step along this path is provided in Andreoni and Sprenger (2012b).

\section{REFERENCES}

Allais, Maurice. 1953. "Le Comportement de l'Homme Rationnel devant le Risque: Critique des Postulats et Axiomes de 1'Ecole Americaine." Econometrica 21 (4): 503-46.

Anderhub, Vital, Werner Güth, Uri Gneezy, and Doron Sonsino. 2001. "On the Interaction of Risk and Time Preferences: An Experimental Study.” German Economic Review 2 (3): 239-53. 
Andersen, Steffen, Glenn W. Harrison, Morten I. Lau, and E. Elisabet Rutström. 2008. "Eliciting Risk and Time Preferences." Econometrica 76 (3): 583-618.

Andreoni, James, and Charles Sprenger. 2012a. "Estimating Time Preferences from Convex Budgets: Dataset." American Economic Review. http://dx.doi.org/10.1257/aer.102.7.3333.

Andreoni, James, and Charles Sprenger. 2012b. "Risk Preferences Are Not Time Preferences." American Economic Review 102 (7): 3357-76.

Ashraf, Nava, Dean Karlan, and Wesley Yin. 2006. "Tying Odysseus to the Mast: Evidence from a Commitment Savings Product in the Philippines." Quarterly Journal of Economics 121 (2): 635-72.

Benhabib, Jess, Alberto Bisin, and Andrew Schotter. 2010. "Present-Bias, Quasi-hyperbolic Discounting, and Fixed Costs." Games and Economic Behavior 69 (2): 205-23.

Burks, Stephen, Jeffrey Carpenter, Lorenz Goette, and Aldo Rustichini. 2009. "Cognitive Skills Affect Economic Preferences, Strategic Behavior, and Job Attachment." Proceedings of the National Academy of Sciences 106 (19): 7745-50.

Cagetti, Marco. 2003. "Wealth Accumulation over the Life Cycle and Precautionary Savings." Journal of Business and Economic Statistics 21 (3): 339-53.

Chabris, Christopher F., David Laibson, Carrie L. Morris, Jonathon P. Schuldt, and Dmitry Taubinsky. 2008a. "Individual Laboratory-Measured Discount Rates Predict Field Behavior." Journal of Risk and Uncertainty 37 (2-3): 237-69.

Chabris, Christopher F., David Laibson, Carrie L. Morris, Jonathon P. Schuldt, and Dmitry Taubinsky. 2008b. "Measuring Intertemporal Preferences using Response Times." National Bureau of Economic Research Working Paper 14353.

Coller, Maribeth, and Melonie B. Williams. 1999. "Eliciting Individual Discount Rates.” Experimental Economics 2 (2): 107-27.

Diecidue, Enrico, Ulrich Schmidt, and Peter P. Wakker. 2004. "The Utility of Gambling Reconsidered." Journal of Risk and Uncertainty 29 (3): 241-59.

Dohmen, Thomas, Armin Falk, David Huffman, Uwe Sunde, Juergen Schupp, and Gert G. Wagner. 2005. "Individual Risk Attitudes: New Evidence from a Large, Representative, Experimentally-Validated Survey." Unpublished.

Epstein, Larry G., and Stanley E. Zin. 1989. "Substitution, Risk Aversion, and the Temporal Behavior of Consumption and Asset Returns: A Theoretical Framework." Econometrica 57 (4): 937-69.

-Frederick, Shane, George Loewenstein, and Ted O'Donoghue. 2002. "Time Discounting and Time Preference: A Critical Review.” Journal of Economic Literature 40 (2): 351-401.

Giné, Xavier, Jessica Goldberg, Dan Silverman, and Dean Yang. 2010. "Revising Commitments: Time Preference and Time-Inconsistency in the Field." Unpublished.

Gourinchas, Pierre-Oliver, and Jonathan A. Parker. 2002. "Consumption over the Life Cycle." Econometrica 70 (1): 47-89.

Gul, Faruk, and Wolfgang Pesendorfer. 2001. "Temptation and Self-Control." Econometrica 69 (6): 1403-35.

Halevy, Yoram. 2008. "Strotz Meets Allais: Diminishing Impatience and the Certainty Effect." American Economic Review 98 (3): 1145-62.

Harrison, Glenn W., Morten Igel Lau, E. Elisabet Rutström, and Melonie B. Sullivan. 2005. "Eliciting Risk and Time Preferences Using Field Experiments: Some Methodological Issues.” In Field Experiments in Economics, edited by Jeffrey P. Carpenter, Glenn W. Harrison, and John A. List, 125-218. Amsterdam: Elsevier.

Harrison, Glenn W., Morten I. Lau, and Melonie B. Williams. 2002. "Estimating Individual Discount Rates in Denmark: A Field Experiment." American Economic Review 92 (5): 1606-17.

Hausman, Jerry A. 1979. "Individual Discount Rates and the Purchase and Utilization of EnergyUsing Durables.” Bell Journal of Economics 10 (1): 33-54.

Holt, Charles A., and Susan K. Laury. 2002. "Risk Aversion and Incentive Effects." American Economic Review 92 (5): 1644-55.

Jacobson, Sarah, and Ragan Petrie. 2009. "Learning from Mistakes: What Do Inconsistent Choices over Risk Tell Us?" Journal of Risk and Uncertainty 38 (2): 143-58.

Keren, Gideon, and Peter Roelofsma. 1995. "Immediacy and Certainty in Intertemporal Choice." Organizational Behavior and Human Decision Processes 63 (3): 287-97.

Kirby, Kris N., Nancy M. Petry, and Warren K. Bickel. 1999. "Heroin Addicts Have Higher Discount Rates for Delayed Rewards than Non-Drug-Using Controls." Journal of Experimental Psychology: General 128 (1): 78-87.

Kreps, David M., and Evan L. Porteus. 1978. "Temporal Resolution of Uncertainty and Dynamic Choice Theory." Econometrica 46 (1): 185-200.

-Laibson, David. 1997. "Golden Eggs and Hyperbolic Discounting." Quarterly Journal of Economics $112(2): 443-77$. 
Laibson, David, Andrea Repetto, and Jeremy Tobacman. 2003. “A Debt Puzzle.” In Knowledge, Information, and Expectations in Modern Macroeconomics: In Honor of Edmund S. Phelps, edited by Philippe Aghion, Roman Frydma, Joseph Stiglitz, and Michael Woodford, 228-66. Princeton, NJ: Princeton University Press.

Laibson, David, Andrea Repetto, and Jeremy Tobacman. 2005. "Estimating Discount Functions with Consumption Choices over the Lifecycle." Unpublished.

McClure, Samuel, David Laibson, George Loewenstein, and Jonathan Cohen. 2004. "Separate Neural Systems Value Immediate and Delayed Monetary Rewards.” Science 306 (5695): 503-07.

McClure, Samuel, Keith M. Ericson, David Laibson, George Loewenstein, and Jonathan Cohen. 2007. "Time Discounting for Primary Rewards." Journal of Neuroscience 27 (21): 5796-804.

-Meier, Stephan, and Charles Sprenger. 2010. "Present-Biased Preferences and Credit Card Borrowing." American Economic Journal: Applied Economics 2 (1): 193-210.

Neilson, William S. 1992. "Some Mixed Results on Boundary Effects." Economics Letters 39 (3): 275-78.

Noor, Jawwad. 2009. "Hyperbolic Discounting and the Standard Model: Eliciting Discount Functions." Journal of Economic Theory 144 (5): 2077-83.

Noor, Jawwad. 2011. “Time Preference: Experiments and Foundations.” Unpublished.

O'Donoghue, Ted, and Matthew Rabin. 1999. "Doing It Now or Later." American Economic Review 89 (1): 103-24.

Phelps, E. S., and R. A. Pollak. 1968. "On Second-Best National Saving and Game-Equilibrium Growth." Review of Economic Studies 35 (2): 185-99.

Rabin, Matthew. 2000. "Risk Aversion and Expected-Utility Theory: A Calibration Theorem." Econometrica 68 (5): 1281-92.

Read, Daniel, and Barbara van Leeuwen. 1998. "Predicting Hunger: The Effects of Appetite and Delay on Choice." Organizational Behavior and Human Decision Processes 76 (2): 189-205.

Reuben, Ernesto, Paola Sapienza, and Luigi Zingales. 2010. "Time Discounting for Primary and Monetary Rewards." Economics Letters 106 (2): 125-27.

-Schmidt, Ulrich. 1998. "A Measurement of the Certainty Effect." Journal of Mathematical Psychology 42 (1): 32-47.

Schoemaker, Paul J. H. 1982. "The Expected Utility Model: Its Variants, Purposes, Evidence and Limitations." Journal of Economic Literature 20 (2): 529-63.

-Selden, Larry. 1978. “A New Representation of Preferences over 'Certain A Uncertain' Consumption Pairs: The 'Ordinal Certainty Equivalent' Hypothesis.” Econometrica 46 (5): 1045-60.

-Strotz, R. H. 1956. "Myopia and Inconsistency in Dynamic Utility Maximization." Review of Economic Studies 23 (3): 165-80.

Tanaka, Tomomi, Colin F. Camerer, and Quang Nguyen. 2010. "Risk and Time Preferences: Linking Experimental and Household Survey Data from Vietnam." American Economic Review 100 (1): 557-71.

Weber, Bethany J., and Gretchen B. Chapman. 2005. "The Combined Effects of Risk and Time on Choice: Does Uncertainty Eliminate the Immediacy Effect? Does Delay Eliminate the Certainty Effect?" Organizational Behavior and Human Decision Processes 96 (2): 104-18.

Wooldridge, Jeffrey M. 2002. Econometric Analysis of Cross Section and Panel Data. Cambridge, MA: MIT Press. 


\section{This article has been cited by:}

1. Shuoli Zhao, Chengyan Yue. 2020. Risk preferences of commodity crop producers and specialty crop producers: An application of prospect theory. Agricultural Economics 42. . [Crossref]

2. Elisa De Marchi, Alessia Cavaliere, Alessandro Banterle. 2020. Consumers' Choice Behavior for Cisgenic Food: Exploring the Role of Time Preferences. Applied Economic Perspectives and Policy 83. . [Crossref]

3. Sarah Walker. 2020. Historical legacies in savings: Evidence from Romania. Journal of Comparative Economics 48:1, 76-99. [Crossref]

4. Remidius Denis Ruhinduka, Yonas Alem, Håkan Eggert, Travis Lybbert. 2020. Smallholder rice farmers' post-harvest decisions: preferences and structural factors. European Review of Agricultural Economics 67. . [Crossref]

5. Anett John. 2020. When Commitment Fails: Evidence from a Field Experiment. Management Science 66:2, 503-529. [Crossref]

6. James Andreoni, Alison Sanchez. 2020. FOOLING MYSELF OR FOOLING OBSERVERS? AVOIDING SOCIAL PRESSURES BY MANIPULATING PERCEPTIONS OF DESERVINGNESS OF OTHERS. Economic Inquiry 58:1, 12-33. [Crossref]

7. Zachary Breig. 2020. Prediction and Model Selection in Experiments. Economic Record . [Crossref]

8. Patrick DeJarnette, David Dillenberger, Daniel Gottlieb, Pietro Ortoleva. 2020. Time Lotteries and Stochastic Impatience. Econometrica 88:2, 619-656. [Crossref]

9. Shotaro Shiba, Kazumi Shimizu. 2019. Does time inconsistency differ between gain and loss? An intrapersonal comparison using a non-parametric elicitation method. Theory and Decision 102. . [Crossref]

10. Michael Callen, Suresh de Mel, Craig McIntosh, Christopher Woodruff. 2019. What Are the Headwaters of Formal Savings? Experimental Evidence from Sri Lanka. The Review of Economic Studies 86:6, 2491-2529. [Crossref]

11. Nicolas Drouhin. 2019. Non-stationary additive utility and time consistency. Journal of Mathematical Economics . [Crossref]

12. Matthew Gnagey, Therese Grijalva, Rong Rong. 2019. Spousal influence and assortative mating on time preferences: a field experiment in the USA. Review of Economics of the Housebold 35. . [Crossref]

13. Julia Rose, Michael Rose. 2019. Ready-made oTree apps for time preference elicitation methods. Journal of Behavioral and Experimental Finance 23, 23-28. [Crossref]

14. Stephen L. Cheung. 2019. Eliciting utility curvature in time preference. Experimental Economics 59. . [Crossref]

15. Glenn W. Harrison, Jia Min Ng. 2019. Behavioral insurance and economic theory: A literature review. Risk Management and Insurance Review 22:2, 133-182. [Crossref]

16. Markus Dertwinkel-Kalt, Mats Köster, Florian Peiseler. 2019. Attention-driven demand for bonus contracts. European Economic Review 115, 1-24. [Crossref]

17. Chen Lian, Yueran Ma, Carmen Wang. 2019. Low Interest Rates and Risk-Taking: Evidence from Individual Investment Decisions. The Review of Financial Studies 32:6, 2107-2148. [Crossref]

18. Sally Sadoff, Anya Samek, Charles Sprenger. 2019. Dynamic Inconsistency in Food Choice: Experimental Evidence from Two Food Deserts. The Review of Economic Studies 105. . [Crossref]

19. Ned Augenblick, Matthew Rabin. 2019. An Experiment on Time Preference and Misprediction in Unpleasant Tasks. The Review of Economic Studies 86:3, 941-975. [Crossref] 
20. Mohammed Abdellaoui, Emmanuel Kemel, Amma Panin, Ferdinand M. Vieider. 2019. Measuring time and risk preferences in an integrated framework. Games and Economic Bebavior 115, 459-469. [Crossref]

21. Sule Alan, Teodora Boneva, Seda Ertac. 2019. Ever Failed, Try Again, Succeed Better: Results from a Randomized Educational Intervention on Grit*. The Quarterly Journal of Economics 126. . [Crossref]

22. Sule Alan, Seda Ertac, Mert Gumren. 2019. Cheating and incentives in a performance context: Evidence from a field experiment on children. Journal of Economic Bebavior \& Organization . [Crossref]

23. Marco Castillo, Jeffrey L Jordan, Ragan Petrie. 2019. Discount Rates of Children and High School Graduation. The Economic Journal 129:619, 1153-1181. [Crossref]

24. Kirsten I. M. Rohde. 2019. Measuring Decreasing and Increasing Impatience. Management Science 65:4, 1700-1716. [Crossref]

25. Silvia Lopez-Guzman, Anna B. Konova, Paul W. Glimcher. 2019. Computational psychiatry of impulsivity and risk: how risk and time preferences interact in health and disease. Philosophical Transactions of the Royal Society B: Biological Sciences 374:1766, 20180135. [Crossref]

26. Alastair Irvine, Marjon van der Pol, Euan Phimister. 2019. A comparison of professional and private time preferences of General Practitioners. Social Science \& Medicine 222, 256-264. [Crossref]

27. Takahiro Miura. 2019. Does time preference affect smoking behavior? A dynamic panel analysis. Journal of Behavioral and Experimental Economics 78, 170-180. [Crossref]

28. Rong Rong, Therese C. Grijalva, Jayson Lusk, W. Douglass Shaw. 2019. Interpersonal discounting. Journal of Risk and Uncertainty 58:1, 17-42. [Crossref]

29. Keith Marzilli Ericson, David Laibson. Intertemporal choice 1-67. [Crossref]

30. Michael Kremer, Gautam Rao, Frank Schilbach. Behavioral development economics 345-458. [Crossref]

31. Matthias Sutter, Claudia Zoller, Daniela Glätzle-Rützler. 2019. Economic behavior of children and adolescents - A first survey of experimental economics results. European Economic Review 111, 98-121. [Crossref]

32. Isabelle Brocas, Juan D. Carrillo, T. Dalton Combs, Niree Kodaverdian. 2019. Consistency in simple vs. complex choices by younger and older adults. Journal of Economic Bebavior \& Organization 157, 580-601. [Crossref]

33. Moritz Lukas, Markus Noeth. 2019. What Induces Children to Save (More)?. SSRN Electronic Journal . [Crossref]

34. Michael M. Bechtel, Amalie Sofie Jensen, Kenneth F. Scheve. 2019. Measuring Time Preferences in Large Surveys. SSRN Electronic Journal . [Crossref]

35. Diego Aycinena, Szabolcs Blazsek, Lucas Rentschler, Betzy Sandoval. 2019. Smoothing, discounting, and demand for intra-household control for recipients of conditional cash transfers. Journal of Applied Economics 22:1, 219-242. [Crossref]

36. Alexis Direr. 2019. Bringing Present Bias Back to the Present. SSRN Electronic Journal . [Crossref]

37. Zachary Breig, Matthew Gibson, Jeffrey Shrader. 2019. Why Do We Procrastinate? Present Bias and Optimism. SSRN Electronic Journal . [Crossref]

38. Sabine Fischer, Meike Wollni. 2018. The role of farmers' trust, risk and time preferences for contract choices: Experimental evidence from the Ghanaian pineapple sector. Food Policy 81, 67-81. [Crossref]

39. Ehsan Taheri, Chen Wang. 2018. Eliciting Public Risk Preferences in Emergency Situations. Decision Analysis 15:4, 223-241. [Crossref] 
40. Tristan Le Cotty, Elodie Maître d'Hôtel, Raphael Soubeyran, Julie Subervie. 2018. Linking Risk Aversion, Time Preference and Fertiliser Use in Burkina Faso. The Journal of Development Studies 54:11, 1991-2006. [Crossref]

41. Kimberly S. Wolske, Annika Todd, Michael Rossol, James McCall, Benjamin Sigrin. 2018. Accelerating demand for residential solar photovoltaics: Can simple framing strategies increase consumer interest?. Global Environmental Change 53, 68-77. [Crossref]

42. Berno Buechel, Lydia Mechtenberg, Julia Petersen. 2018. If I can do it, so can you! Peer effects on perseverance. Journal of Economic Bebavior \& Organization 155, 301-314. [Crossref]

43. Joshua Blumenstock, Michael Callen, Tarek Ghani. 2018. Why Do Defaults Affect Behavior? Experimental Evidence from Afghanistan. American Economic Review 108:10, 2868-2901. [Abstract] [View PDF article] [PDF with links]

44. Elias Carroni. 2018. Behaviour-based price discrimination with cross-group externalities. Journal of Economics 125:2, 137-157. [Crossref]

45. Yang Wang, Frank A. Sloan. 2018. Present bias and health. Journal of Risk and Uncertainty 57:2, 177-198. [Crossref]

46. Rong Rong, Matthew Gnagey, Therese Grijalva. 2018. "The less you Discount, the more it shows you really care": Interpersonal discounting in households. Journal of Economic Behavior \& Organization 154, 1-23. [Crossref]

47. Therese C. Grijalva, Jayson L. Lusk, Rong Rong, W. Douglass Shaw. 2018. Convex Time Budgets and Individual Discount Rates in the Long Run. Environmental and Resource Economics 71:1, 259-277. [Crossref]

48. Isabelle Brocas, Juan D. Carrillo, Jorge Tarrasó. 2018. How long is a minute?. Games and Economic Bebavior 111, 305-322. [Crossref]

49. Derek Lemoine. 2018. Age-induced acceleration of time: Implications for intertemporal choice. Journal of Economic Behavior \& Organization 153, 143-152. [Crossref]

50. Matthew Gnagey, Therese Grijalva, Rong Rong. 2018. Spousal Dictator Game: Household Decisions and Other-Regarding Preferences. Games 9:3, 69. [Crossref]

51. Yan Chen, Ming Jiang, Erin L. Krupka. 2018. Hunger and the gender gap. Experimental Economics 24. . [Crossref]

52. Melanie Lührmann, Marta Serra-Garcia, Joachim Winter. 2018. The Impact of Financial Education on Adolescents' Intertemporal Choices. American Economic Journal: Economic Policy 10:3, 309-332. [Abstract] [View PDF article] [PDF with links]

53. Matthias Sutter, Silvia Angerer, Daniela Glätzle-Rützler, Philipp Lergetporer. 2018. Language group differences in time preferences: Evidence from primary school children in a bilingual city. European Economic Review 106, 21-34. [Crossref]

54. Barbara Fischer, Harry Telser, Peter Zweifel. 2018. End-of-life healthcare expenditure: Testing economic explanations using a discrete choice experiment. Journal of Health Economics 60, 30-38. [Crossref]

55. Emla Fitzsimons, Bansi Malde, Marcos Vera-Hernández. 2018. Group Size and the Efficiency of Informal Risk Sharing. The Economic Journal 128:612, F575-F608. [Crossref]

56. Pavlo R. Blavatskyy, Hela Maafi. 2018. Estimating representations of time preferences and models of probabilistic intertemporal choice on experimental data. Journal of Risk and Uncertainty 56:3, 259-287. [Crossref]

57. Franz Fuerst, Ramandeep Singh. 2018. How present bias forestalls energy efficiency upgrades: A study of household appliance purchases in India. Journal of Cleaner Production 186, 558-569. [Crossref] 
58. Arthur E. Attema, Han Bleichrodt, Olivier L'Haridon, Patrick Peretti-Watel, Valérie Seror. 2018. Discounting health and money: New evidence using a more robust method. Journal of Risk and Uncertainty 56:2, 117-140. [Crossref]

59. Stefano DellaVigna, Devin Pope. 2018. What Motivates Effort? Evidence and Expert Forecasts. The Review of Economic Studies 85:2, 1029-1069. [Crossref]

60. Dan Anderberg, Helmut Rainer, Kerstin Roeder. 2018. Family-specific investments and divorce with dynamically inconsistent households: Marital contracts and policy. Journal of Economic Bebavior \& Organization 148, 199-225. [Crossref]

61. Te Bao, Yun Dai, Xiaohua Yu. 2018. Memory and discounting: Theory and evidence. Journal of Economic Dynamics and Control 88, 21-30. [Crossref]

62. Kitae Sohn. 2018. How does the ordering of questions affect elicited time preferences?. Applied Economics Letters 25:4, 244-248. [Crossref]

63. Kristina Esopo, Daniel Mellow, Catherine Thomas, Hannah Uckat, Justin Abraham, Prachi Jain, Chaning Jang, Nicholas Otis, Michala Riis-Vestergaard, Amanda Starcev, Kate Orkin, Johannes Haushofer. 2018. Measuring self-efficacy, executive function, and temporal discounting in Kenya. Bebaviour Research and Therapy 101, 30-45. [Crossref]

64. Xavier Giné, Jessica Goldberg, Dan Silverman, Dean Yang. 2018. Revising Commitments: Field Evidence on the Adjustment of Prior Choices. The Economic Journal 128:608, 159-188. [Crossref]

65. Robin Cubitt, Rebecca McDonald, Daniel Read. 2018. Time Matters Less When Outcomes Differ: Unimodal vs. Cross-Modal Comparisons in Intertemporal Choice. Management Science 64:2, 873-887. [Crossref]

66. Silvia Lopez-Guzman, Anna B. Konova, Kenway Louie, Paul W. Glimcher. 2018. Risk preferences impose a hidden distortion on measures of choice impulsivity. PLOS ONE 13:1, e0191357. [Crossref]

67. Diego Aycinena, Lucas Rentschler. 2018. Discounting and Digit Ratio: Low 2D:4D Predicts Patience for a Sample of Females. Frontiers in Behavioral Neuroscience 11. . [Crossref]

68. Stefano DellaVigna. Structural Behavioral Economics 613-723. [Crossref]

69. Olympia Bover, Laura Hospido, Ernesto Villanueva. 2018. The Impact of High School Financial Education on Financial Knowledge and Choices: Evidence from a Randomized Trial in Spain. SSRN Electronic Journal . [Crossref]

70. Joshua Lanier, Bin Miao, John Kim-Ho Quah, Songfa Zhong. 2018. Intertemporal Consumption With Risk: A Revealed Preference Analysis. SSRN Electronic Journal . [Crossref]

71. Victor Stango, Joanne Yoong, Jonathan Zinman. 2018. Quicksand or Bedrock for Behavioral Economics? Assessing Foundational Empirical Questions. SSRN Electronic Journal . [Crossref]

72. Felix Kölle, Lukas Wenner. 2018. Time-Inconsistent Generosity: Present Bias Across Individual and Social Contexts. SSRN Electronic Journal . [Crossref]

73. Vojtech Bartos, Michal Bauer, Julie Chytilová, Ian Levely. 2018. Effects of Poverty on Impatience: Preferences or Inattention?. SSRN Electronic Journal . [Crossref]

74. Felix Kölle, Thomas Lauer. 2018. Cooperation, Discounting, and the Effects of Delayed Costs and Benefits. SSRN Electronic Journal . [Crossref]

75. Francesco D'Acunto. 2018. Identity and Choice Under Risk. SSRN Electronic Journal . [Crossref]

76. C. Königsheim, M. Lukas, M. Nöth. 2018. Individual preferences and the exponential growth bias. Journal of Economic Behavior \& Organization 145, 352-369. [Crossref]

77. Xiu Chen, Xiaojian Zhao. 2018. How Time Flies!. SSRN Electronic Journal . [Crossref]

78. Liam Delaney, Leonhard K. Lades. 2017. Present Bias and Everyday Self-Control Failures: A Day Reconstruction Study. Journal of Behavioral Decision Making 30:5, 1157-1167. [Crossref] 
79. David Bradford, Charles Courtemanche, Garth Heutel, Patrick McAlvanah, Christopher Ruhm. 2017. Time preferences and consumer behavior. Journal of Risk and Uncertainty 55:2-3, 119-145. [Crossref]

80. Daniel Read, Christopher Y. Olivola, David J. Hardisty. 2017. The Value of Nothing: Asymmetric Attention to Opportunity Costs Drives Intertemporal Decision Making. Management Science 63:12, 4277-4297. [Crossref]

81. Sébastien Ménard, Coralia Quintero. 2017. Ausentismo y producción: el esquema de ajuste de primas por siniestralidad observada aplicado al seguro de salud en Francia. Lecturas de Economía :88, 9-50. [Crossref]

82. Daniele Pennesi. 2017. Uncertain discount and hyperbolic preferences. Theory and Decision 83:3, 315-336. [Crossref]

83. \#\#, CHOIMINSIK, \#\#\#. 2017. Time Preference and Economic Decision Making in Aging: Focusing on Implications for Economics Education. Journal of Research in Curriculum Instruction 21:5, 564-576. [Crossref]

84. Giorgia Barboni. 2017. Repayment flexibility in microfinance contracts: Theory and experimental evidence on take up and selection. Journal of Economic Behavior \& Organization 142, 425-450. [Crossref]

85. Anujit Chakraborty, Evan M. Calford, Guidon Fenig, Yoram Halevy. 2017. External and internal consistency of choices made in convex time budgets. Experimental Economics 20:3, 687-706. [Crossref]

86. Ismael Rodriguez-Lara, Giovanni Ponti. 2017. Social motives vs social influence: An experiment on interdependent time preferences. Games and Economic Behavior 105, 177-194. [Crossref]

87. Ki-Eun Rhee, Raphael Thomadsen. 2017. Behavior-Based Pricing in Vertically Differentiated Industries. Management Science 63:8, 2729-2740. [Crossref]

88. Rachid Laajaj. 2017. Endogenous time horizon and behavioral poverty trap: Theory and evidence from Mozambique. Journal of Development Economics 127, 187-208. [Crossref]

89. Salvador Cruz Rambaud, María J. Muñoz Torrecillas, Taiki Takahashi. 2017. Observed and Normative Discount Functions in Addiction and other Diseases. Frontiers in Pharmacology 8. . [Crossref]

90. Daniel Read, Marc Scholten. Future-Oriented Decisions: Intertemporal Choice 35-50. [Crossref]

91. Florian Lindner, Julia Rose. 2017. No need for more time: Intertemporal allocation decisions under time pressure. Journal of Economic Psychology 60, 53-70. [Crossref]

92. Alessandra Cassar, Andrew Healy, Carl von Kessler. 2017. Trust, Risk, and Time Preferences After a Natural Disaster: Experimental Evidence from Thailand. World Development 94, 90-105. [Crossref]

93. Marcel Stadelmann. 2017. Mind the gap? Critically reviewing the energy efficiency gap with empirical evidence. Energy Research \& Social Science 27, 117-128. [Crossref]

94. Wendy Janssens, Berber Kramer, Lisette Swart. 2017. Be patient when measuring hyperbolic discounting: Stationarity, time consistency and time invariance in a field experiment. Journal of Development Economics 126, 77-90. [Crossref]

95. Michael A. Kuhn, Peter Kuhn, Marie Claire Villeval. 2017. Decision-environment effects on intertemporal financial choices: How relevant are resource-depletion models?. Journal of Economic Behavior \& Organization 137, 72-89. [Crossref]

96. Hiroki Nishimura, Efe A. Ok, John K.-H. Quah. 2017. A Comprehensive Approach to Revealed Preference Theory. American Economic Review 107:4, 1239-1263. [Abstract] [View PDF article] [PDF with links]

97. Laurent Denant-Boemont, Enrico Diecidue, Olivier l'Haridon. 2017. Patience and time consistency in collective decisions. Experimental Economics 20:1, 181-208. [Crossref] 
98. Sophie Clot, Charlotte Y. Stanton, Marc Willinger. 2017. Are impatient farmers more risk-averse? Evidence from a lab-in-the-field experiment in rural Uganda. Applied Economics 49:2, 156-169. [Crossref]

99. Chengyan Yue, Jingjing Wang. Temporal Discounting of Future Risks 253-265. [Crossref]

100. Victor Stango, Joanne Yoong, Jonathan Zinman. 2017. The Quest for Parsimony in Behavioral Economics: New Methods and Evidence on Three Fronts. SSRN Electronic Journal . [Crossref]

101. Victor Stango, Joanne Yoong, Jonathan Zinman. 2017. Quicksand or Bedrock for Behavioral Economics? Assessing Foundational Empirical Questions. SSRN Electronic Journal . [Crossref]

102. Victor Aguiar, Nail Kashaev. 2017. Stochastic Revealed Preferences with Measurement Error: Testing for Exponential Discounting in Survey Data. SSRN Electronic Journal . [Crossref]

103. Charlotte Ringdal, Ingrid Hoem Sjursen. 2017. Household Bargaining and Spending on Children: Experimental Evidence from Tanzania. SSRN Electronic Journal . [Crossref]

104. Nicolas Drouhin. 2017. Non-Stationary Additive Utility and Time Consistency. SSRN Electronic Journal . [Crossref]

105. Jeffrey P. Carpenter, Emiliano Huet-Vaughn, Peter Hans Matthews, Andrea Robbett, Dustin Beckett, Julian C. Jamison. 2017. Choice Architecture to Improve Financial Decision Making. SSRN Electronic Journal . [Crossref]

106. Rong Rong, Therese C. Grijalva, Jayson Lusk, W. Douglass Shaw. 2017. Interpersonal Discounting. SSRN Electronic Journal . [Crossref]

107. Daniel Hermann, Oliver Musshoff. 2016. Measuring time preferences: Comparing methods and evaluating the magnitude effect. Journal of Behavioral and Experimental Economics 65, 16-26. [Crossref]

108. Grant Graziani, Wilbert van der Klaauw, Basit Zafar. 2016. Workers' Spending Response to the 2011 Payroll Tax Cuts. American Economic Journal: Economic Policy 8:4, 124-159. [Abstract] [View PDF article] [PDF with links]

109. Venkataraghavan Krishnaswamy, Aseem Pahuja, R. P. Sundarraj. 2016. Integrating Time-Preferences into E-Negotiation Systems: A Model, Elicitation Approach and Experimental Implications. Group Decision and Negotiation 25:6, 1137-1167. [Crossref]

110. Omar Al-Ubaydli, Garett Jones, Jaap Weel. 2016. Average player traits as predictors of cooperation in a repeated prisoner's dilemma. Journal of Behavioral and Experimental Economics 64, 50-60. [Crossref]

111. Daniel Hermann, Oliver Musshoff. 2016. Anchoring effects in experimental discount rate elicitation. Applied Economics Letters 23:14, 1022-1025. [Crossref]

112. Alexander Schuhr. 2016. Seizing Control: Estimating Multiple Decision Processes and the Investigation of Self-Control. Basic and Applied Social Psychology 38:5, 241-257. [Crossref]

113. Tim Reutemann, Stefanie Engel, Eliana Pareja. 2016. How (not) to pay - Field experimental evidence on the design of REDD + payments. Ecological Economics 129, 220-229. [Crossref]

114. Stephen L. Cheung. 2016. Recent developments in the experimental elicitation of time preference. Journal of Behavioral and Experimental Finance 11, 1-8. [Crossref]

115. Philipp Schreiber, Martin Weber. 2016. Time inconsistent preferences and the annuitization decision. Journal of Economic Behavior \& Organization 129, 37-55. [Crossref]

116. Alina Ferecatu, Ayse Önçüler. 2016. Heterogeneous risk and time preferences. Journal of Risk and Uncertainty 53:1, 1-28. [Crossref]

117. Erwin Bulte, Robert Lensink, Nhung Vu. 2016. Gender training and female empowerment: Experimental evidence from Vietnam. Economics Letters 145, 117-119. [Crossref] 
118. Elisa De Marchi, Vincenzina Caputo, Rodolfo M. Nayga, Alessandro Banterle. 2016. Time preferences and food choices: Evidence from a choice experiment. Food Policy 62, 99-109. [Crossref]

119. Arthur E. Attema, Han Bleichrodt, Yu Gao, Zhenxing Huang, Peter P. Wakker. 2016. Measuring Discounting without Measuring Utility. American Economic Review 106:6, 1476-1494. [Abstract] [View PDF article] [PDF with links]

120. David Freeman, Paola Manzini, Marco Mariotti, Luigi Mittone. 2016. Procedures for eliciting time preferences. Journal of Economic Behavior \& Organization 126, 235-242. [Crossref]

121. Leandro S. Carvalho, Silvia Prina, Justin Sydnor. 2016. The effect of saving on risk attitudes and intertemporal choices. Journal of Development Economics 120, 41-52. [Crossref]

122. Xiaojun Yang, Fredrik Carlsson. 2016. Influence and choice shifts in households: An experimental investigation. Journal of Economic Psychology 53, 54-66. [Crossref]

123. Michaela Pagel. 2016. EXPECTATIONS-BASED REFERENCE-DEPENDENT PREFERENCES AND ASSET PRICING. Journal of the European Economic Association 14:2, 468-514. [Crossref]

124. Leandro S. Carvalho, Stephan Meier, Stephanie W. Wang. 2016. Poverty and Economic DecisionMaking: Evidence from Changes in Financial Resources at Payday. American Economic Review 106:2, 260-284. [Abstract] [View PDF article] [PDF with links]

125. Jessica B. Hoel, Benjamin Schwab, John Hoddinott. 2016. Self-control exertion and the expression of time preference: Experimental results from Ethiopia. Journal of Economic Psychology 52, 136-146. [Crossref]

126. Diego Ubfal. 2016. How general are time preferences? Eliciting good-specific discount rates. Journal of Development Economics 118, 150-170. [Crossref]

127. B. Douglas Bernheim. 2016. The Good, the Bad, and the Ugly: A Unified Approach to Behavioral Welfare Economics. Journal of Benefit-Cost Analysis 7:1, 12-68. [Crossref]

128. Katsunori OGAWA. 2016. Time Discounting Preference, Risk Aversion, and Educational Expectation among High School Students:. The Journal of Educational Sociology 98:0, 135-154. [Crossref]

129. Franz Fuerst. 2016. Harvesting the Low-Hanging Fruit: A Behavioural Study of Energy-Efficient Household Appliance Purchases in India. SSRN Electronic Journal . [Crossref]

130. Horatio Cuesdeanu, Jens Carsten Jackwerth. 2016. The Pricing Kernel Puzzle: Survey and Outlook. SSRN Electronic Journal . [Crossref]

131. Aniko Oery. 2016. Consumers on a Leash: Advertised Sales and Intertemporal Price Discrimination. SSRN Electronic Journal . [Crossref]

132. Jianjun Tang, W. George Hutchinson, Susan M. Chilton, Ruth Hunter, Morten I. Lau, Frank Kee. 2016. Exponential or Hyperbolic? Identifying and Testing the Predictive Power of Time Preference Over Unhealthy Behaviours. SSRN Electronic Journal . [Crossref]

133. L. Cherchye. 2016. Normality of Demand in a Two-Goods Setting. SSRN Electronic Journal . [Crossref]

134. Jonathan Beauchamp, Daniel J. Benjamin, Christopher F. Chabris, David I. Laibson. 2016. Controlling for the Compromise Effect Debiases Estimates of Risk Preference Parameters. SSRN Electronic Journal . [Crossref]

135. C. Oscar Lau. 2016. Disentangling Intertemporal Substitution and Risk Aversion under the Expected Utility Theorem. SSRN Electronic Journal . [Crossref]

136. Mickael Beaud, Marc Willinger. 2016. Quels déterminants de la prise de risque? Les réponses de l'économie expérimentale. L'Actualité économique 92:1-2, 49-79. [Crossref] 
137. Silvia Angerer, Philipp Lergetporer, Daniela Glätzle-Rützler, Matthias Sutter. 2015. How to measure time preferences in children: a comparison of two methods. Journal of the Economic Science Association $1: 2,158-169$. [Crossref]

138. Matthew O. Jackson, Leeat Yariv. 2015. Collective Dynamic Choice: The Necessity of Time Inconsistency. American Economic Journal: Microeconomics 7:4, 150-178. [Abstract] [View PDF article] [PDF with links]

139. Francesca de Nicola. 2015. The impact of weather insurance on consumption, investment, and welfare. Quantitative Economics 6:3, 637-661. [Crossref]

140. Michael Callen. 2015. Catastrophes and time preference: Evidence from the Indian Ocean Earthquake. Journal of Economic Behavior \& Organization 118, 199-214. [Crossref]

141. Ernesto Reuben, Paola Sapienza, Luigi Zingales. 2015. Procrastination and impatience. Journal of Bebavioral and Experimental Economics 58, 63-76. [Crossref]

142. Andrew G. Meyer. 2015. The impacts of elicitation mechanism and reward size on estimated rates of time preference. Journal of Behavioral and Experimental Economics 58, 132-148. [Crossref]

143. Magnus Hatlebakk. 2015. Myopic preferences or subsistence income among rickshaw cyclists. International Journal of Development Issues 14:3, 204-214. [Crossref]

144. Hunt Allcott, Dmitry Taubinsky. 2015. Evaluating Behaviorally Motivated Policy: Experimental Evidence from the Lightbulb Market. American Economic Review 105:8, 2501-2538. [Abstract] [View PDF article] [PDF with links]

145. Anke Gerber, Kirsten I.M. Rohde. 2015. Eliciting discount functions when baseline consumption changes over time. Journal of Economic Bebavior \& Organization 116, 56-64. [Crossref]

146. James Andreoni, Michael A. Kuhn, Charles Sprenger. 2015. Measuring time preferences: A comparison of experimental methods. Journal of Economic Behavior \& Organization 116, 451-464. [Crossref]

147. Ned Augenblick, Muriel Niederle, Charles Sprenger. 2015. Working over Time: Dynamic Inconsistency in Real Effort Tasks*. The Quarterly Journal of Economics 130:3, 1067-1115. [Crossref]

148. Stephen L. Cheung. 2015. Comment on "Risk Preferences Are Not Time Preferences": On the Elicitation of Time Preference under Conditions of Risk. American Economic Review 105:7, 2242-2260. [Abstract] [View PDF article] [PDF with links]

149. Bin Miao, Songfa Zhong. 2015. Comment on "Risk Preferences Are Not Time Preferences": Separating Risk and Time Preference. American Economic Review 105:7, 2272-2286. [Abstract] [View PDF article] [PDF with links]

150. James Andreoni, Charles Sprenger. 2015. Risk Preferences Are Not Time Preferences: Reply. American Economic Review 105:7, 2287-2293. [Abstract] [View PDF article] [PDF with links]

151. Robin Chark, Soo Hong Chew, Songfa Zhong. 2015. Extended present bias: a direct experimental test. Theory and Decision 79:1, 151-165. [Crossref]

152. Silvia Angerer, Daniela Glätzle-Rützler, Philipp Lergetporer, Matthias Sutter. 2015. Donations, risk attitudes and time preferences: A study on altruism in primary school children. Journal of Economic Bebavior \& Organization 115, 67-74. [Crossref]

153. Sule Alan, Seda Ertac. 2015. Patience, self-control and the demand for commitment: Evidence from a large-scale field experiment. Journal of Economic Behavior \& Organization 115, 111-122. [Crossref]

154. Garth Heutel. 2015. Optimal policy instruments for externality-producing durable goods under present bias. Journal of Environmental Economics and Management 72, 54-70. [Crossref]

155. Emel Filiz-Ozbay, Jonathan Guryan, Kyle Hyndman, Melissa Kearney, Erkut Y. Ozbay. 2015. Do lottery payments induce savings behavior? Evidence from the lab. Journal of Public Economics 126, 1-24. [Crossref] 
156. Charles Sprenger. 2015. Judging Experimental Evidence on Dynamic Inconsistency. American Economic Review 105:5, 280-285. [Abstract] [View PDF article] [PDF with links]

157. Stephan Meier, Charles D. Sprenger. 2015. Temporal Stability of Time Preferences. Review of Economics and Statistics 97:2, 273-286. [Crossref]

158. Simone Schaner. 2015. Do Opposites Detract? Intrahousehold Preference Heterogeneity and Inefficient Strategic Savings. American Economic Journal: Applied Economics 7:2, 135-174. [Abstract] [View PDF article] [PDF with links]

159. Derek Lemoine. 2015. Aging and Perspective: Dynamically Consistent Hyperbolic Discounting. SSRN Electronic Journal . [Crossref]

160. Sally Sadoff, Anya Savikhin Samek, Charles Sprenger. 2015. Dynamic Inconsistency in Food Choice: Experimental Evidence from a Food Desert. SSRN Electronic Journal . [Crossref]

161. Sebastian Ebert, Gijs van de Kuilen. 2015. Measuring Multivariate Risk Preferences. SSRN Electronic Journal . [Crossref]

162. Wendy Janssens, Berber Kramer, Lisette Swart. 2015. Be Patient When Measuring Hyperbolic Discounting: Stationarity, Time Consistency and Time Invariance in a Field Experiment. SSRN Electronic Journal . [Crossref]

163. Francesco D'Acunto. 2015. Identity, Overconfidence, and Investment Decisions. SSRN Electronic Journal . [Crossref]

164. Chie Hanaoka, Shinsuke Ikeda, Fumio Ohtake. 2015. Elicitation Designs and Time Discounting: Comparison of Predictive Power on Behavior. SSRN Electronic Journal . [Crossref]

165. Andrew G. Meyer. 2015. Explaining the Fixed Cost Component of Discounting: The Importance of Students' Liquidity Constraints. SSRN Electronic Journal . [Crossref]

166. Matija Kovacic, Francesco Costantini, Juliana Bernhofer. 2015. Risk Attitudes, Investment Behavior and Linguistic Variation: An IV Approach. SSRN Electronic Journal . [Crossref]

167. Yoram Halevy. 2015. Time Consistency: Stationarity and Time Invariance. Econometrica 83:1, 335-352. [Crossref]

168. James A. Feigenbaum, T. Scott Findley. 2015. Quasi-Hyperbolic Discounting and Delayed Retirement. Theoretical Economics Letters 05:02, 325-331. [Crossref]

169. Abi Adams, Laurens Cherchye, Bram De Rock, Ewout Verriest. 2014. Consume Now or Later? Time Inconsistency, Collective Choice, and Revealed Preference. American Economic Review 104:12, 4147-4183. [Abstract] [View PDF article] [PDF with links]

170. Matthew O. Jackson, Leeat Yariv. 2014. Present Bias and Collective Dynamic Choice in the Lab. American Economic Review 104:12, 4184-4204. [Abstract] [View PDF article] [PDF with links]

171. Sophie Clot, Charlotte Y. Stanton. 2014. Present bias predicts participation in payments for environmental services: Evidence from a behavioral experiment in Uganda. Ecological Economics 108, 162-170. [Crossref]

172. Kadir Atalay, Fayzan Bakhtiar, Stephen Cheung, Robert Slonim. 2014. Savings and prize-linked savings accounts. Journal of Economic Behavior \& Organization 107, 86-106. [Crossref]

173. Joshua Tasoff, Robert Letzler. 2014. Everyone believes in redemption: Nudges and overoptimism in costly task completion. Journal of Economic Behavior \& Organization 107, 107-122. [Crossref]

174. Steffen Andersen, Glenn W. Harrison, Morten I. Lau, E. Elisabet Rutström. 2014. Discounting behavior: A reconsideration. European Economic Review 71, 15-33. [Crossref]

175. Therese C. Grijalva, Jayson L. Lusk, W. Douglass Shaw. 2014. Discounting the Distant Future: An Experimental Investigation. Environmental and Resource Economics 59:1, 39-63. [Crossref] 
176. Thomas van Huizen, Janneke Plantenga. 2014. Job Search Behaviour and Time Preferences: Testing Exponential Versus Hyperbolic Discounting. De Economist 162:3, 223-245. [Crossref]

177. Elaine M. Liu, Juanjuan Meng, Joseph Tao-yi Wang. 2014. Confucianism and preferences: Evidence from lab experiments in Taiwan and China. Journal of Economic Bebavior \& Organization 104, 106-122. [Crossref]

178. José Luis Montiel Olea, Tomasz Strzalecki. 2014. Axiomatization and Measurement of QuasiHyperbolic Discounting *. The Quarterly Journal of Economics 129:3, 1449-1499. [Crossref]

179. Andreas C. Drichoutis, Rodolfo M. Nayga. 2014. Do risk and time preferences have biological roots?. Southern Economic Journal 140528150321007. [Crossref]

180. Eric Duquette, Nathaniel Higgins, John Horowitz. 2014. Inferring discount rates from timepreference experiments. Economics Letters 123:2, 212-215. [Crossref]

181. Graham Loomes, Ganna Pogrebna. 2014. Measuring Individual Risk Attitudes when Preferences are Imprecise. The Economic Journal 124:576, 569-593. [Crossref]

182. Alexander L. Brown, Hwagyun Kim. 2014. Do Individuals Have Preferences Used in Macro-Finance Models? An Experimental Investigation. Management Science 60:4, 939-958. [Crossref]

183. Charles A. Holt, Susan K. Laury. Assessment and Estimation of Risk Preferences 135-201. [Crossref]

184. Andrew G. Meyer. 2014. The Impacts of Elicitation Mechanism and Reward Size on Estimated Rates of Time Preference. SSRN Electronic Journal . [Crossref]

185. Mark Dean, Anja Sautmann. 2014. Credit Constraints and the Measurement of Time Preferences. SSRN Electronic Journal . [Crossref]

186. Attila Ambrus, Tinna Laufey Asgeirsdottir, Jawwad Noor, LLszll SSndor. 2014. Compensated Discount Functions - An Experiment on Integrating Rewards with Expected Income. SSRN Electronic Journal . [Crossref]

187. W. Douglass Shaw, Therese C. Grijalva, Jayson L. Lusk, Rong Rong. 2014. Does the Convex Time Budget Approach Lead to Evidence of Hyperbolic Discounting When the Time Horizon is Very Long?. SSRN Electronic Journal . [Crossref]

188. Simone Galperti, Bruno H. Strulovici. 2014. From Anticipations to Present Bias: A Theory of Forward-Looking Preferences. SSRN Electronic Journal . [Crossref]

189. James A. Feigenbaum, T. Scott Findley. 2014. Quasi-Hyperbolic Discounting and Delayed Retirement. SSRN Electronic Journal . [Crossref]

190. Lydia Ashton. 2014. Hunger Games: Does Hunger and Cognitive Fatigue Affect Time Preferences?. SSRN Electronic Journal . [Crossref]

191. Sule Alan, Seda Ertac. 2014. Good Things Come to Those Who (are Taught How to) Wait: Results from a Randomized Educational Intervention on Time Preference. SSRN Electronic Journal . [Crossref]

192. Hunt Allcott, Dmitry Taubinsky. 2014. Evaluating Behaviorally-Motivated Policy: Experimental Evidence from the Lightbulb Market. SSRN Electronic Journal . [Crossref]

193. Lydia Lawless, Andreas C Drichoutis, Rodolfo M Nayga. 2013. Time preferences and health behaviour: a review. Agricultural and Food Economics 1:1. . [Crossref]

194. Andreas C. Drichoutis, Rodolfo M. Nayga. 2013. Eliciting risk and time preferences under induced mood states. The Journal of Socio-Economics 45, 18-27. [Crossref]

195. Géraldine Bocquého, Florence Jacquet, Arnaud Reynaud. 2013. Reversal and magnitude effects in long-term time preferences: Results from a field experiment. Economics Letters 120:1, 108-111. [Crossref] 
196. Gary Charness, Uri Gneezy, Alex Imas. 2013. Experimental methods: Eliciting risk preferences. Journal of Economic Behavior \& Organization 87, 43-51. [Crossref]

197. Dale O. Stahl. 2013. Intertemporal choice with liquidity constraints: Theory and experiment. Economics Letters 118:1, 101-103. [Crossref]

198. Grant Graziani, Wilbert van der Klaauw, Basit Zafar. 2013. A Boost in the Paycheck: Survey Evidence on Workers' Response to the 2011 Payroll Tax Cuts. SSRN Electronic Journal . [Crossref]

199. Michael Kuhn, Peter J. Kuhn, Marie-Claire Villeval. 2013. The Importance of the Cognitive Environment for Intertemporal Choice. SSRN Electronic Journal . [Crossref]

200. Eva Woelbert, Arno Riedl. 2013. Measuring Time and Risk Preferences: Reliability, Stability, Domain Specificity. SSRN Electronic Journal . [Crossref]

201. James Andreoni,, Charles Sprenger. 2012. Risk Preferences Are Not Time Preferences. American Economic Review 102:7, 3357-3376. [Abstract] [View PDF article] [PDF with links]

202. Susan K. Laury, Melayne Morgan McInnes, J. Todd Swarthout. 2012. Avoiding the curves: Direct elicitation of time preferences. Journal of Risk and Uncertainty 44:3, 181-217. [Crossref]

203. Joshua Tasoff, Robert Letzler. 2012. Everyone Believes in Redemption: Overoptimism and Nudges. SSRN Electronic Journal . [Crossref]

204. Bin Miao, Songfa Zhong. 2012. Separating Risk Preference and Time Preference. SSRN Electronic Journal . [Crossref]

205. Matthew R. Levy, Joshua Tasoff. 2012. Exponential-Growth Bias and Lifecycle Consumption. SSRN Electronic Journal . [Crossref]

206. Abi Adams, Laurens Cherchye, Bram De Rock, Ewout Verriest. 2012. Consume Now or Later? Time Inconsistency, Collective Choice and Revealed Preference. SSRN Electronic Journal . [Crossref]

207. Matthew O. Jackson, Leeat Yariv. 2012. Present Bias and Collective Dynamic Choice in the Lab. SSRN Electronic Journal . [Crossref]

208. Michaela Pagel. 2012. Expectations-Based Reference-Dependent Preferences and Asset Pricing. SSRN Electronic Journal . [Crossref]

209. Matthew O. Jackson, Leeat Yariv. 2011. Collective Dynamic Choice: The Necessity of Time Inconsistency. SSRN Electronic Journal . [Crossref] 